\title{
LA CONSOLIDACIÓN DE LA OLIGARQUÍA URBANA EN VINARÒS EN LA SEGUNDA MITAD DEL SIGLO XVIII
}

\section{THE URBAN OLIGARCHY CONSOLIDATION IN VINARÒS IN THE SECOND HALF OF THE EIGHTEENTH CENTURY}

\author{
Gema Barreda Asenjo \\ Universitat Jaume I
}

\begin{abstract}
RESUMEN
Este artículo se ocupa del estudio de la élite urbana en la localidad de Vinaròs de mediados del siglo XVIII. Para ello, primero, identificaremos quiénes eran los individuos que la formaban, así como, los espacios de poder que ocupaban, para posteriormente analizar el papel que jugaban dentro de la sociedad vinarocense durante este periodo. Este trabajo tiene, además, el objetivo de describir el perfil de esta élite, considerando su localización en el poder municipal, sus actividades económicas y procedencia social (cargos y títulos). Este grupo selecto aparece representado en el panorama político y llenando con su presencia el mundo del comercio. Además, nos ha interesado el análisis de los vínculos entrelazados de sus élites, así como, la forma en que estos grupos sociales se mantienen en el poder y lo acrecientan con el tiempo.
\end{abstract}

Palabras clave: Vinaròs, élite local, poder municipal, siglo XVIII, comercio, oligarquía urbana, ascenso social.

\begin{abstract}
In this article we will present the study of the urban elite in Vinaròs in the mid eighteenth century. We will first focus on identifying which individuals formed the elite, in addition to the positions of power which they held. The article will subsequently analyse their role in the society of Vinaròs during this period. Thus, the aim of this paper is to describe the profile of this elite group, considering their place in the local power structure, their business activities and social background (positions and titles). This select group is represented on the political scene and in the world of commerce. In addition, the article studies the interwoven links of elites, as well as the manner in which these social groups maintained themselves in power and enhanced their power over time.
\end{abstract}

Keywords: Vinaròs, local elite, municipal power, xvIIth century, commerce. 
Es indudable que el estudio de las élites y oligarquías urbanas ha suscitado, durante los últimos años, gran interés por parte de diversos investigadores. Al igual que diferentes trabajos vinculados con el patriciado urbano, a través del nuestro descubriremos su organización y disposición, más concretamente en la localidad de Vinaròs, tratando aspectos como la conformación del cabildo municipal, las actividades económicas de sus componentes, además de los mecanismos de afianzamiento y proliferación del poder en la sociedad'.

Con la finalidad de delinear, de la mejor manera posible, los grupos sociales y/o familias que estudiamos, creemos conveniente fijar nuestro análisis abordando el examen de su ascenso político, así como, la configuración por medio de distintas actividades económicas y comerciales que consigue una parte de la sociedad vinarocense a mediados del Setecientos.

\section{Promoción política e institucional. La distribución de los cargos mu- NICIPALES ENTRE LA ÉLITE}

Si hemos de trabajar la personalidad y actuación de la élite en Vinaròs a mediados del XVIII, debemos considerar que este aspecto se despliega en otras categorías -la política, la comercial y la socioeconómica- entre ellas diferenciables pero que en ocasiones se entrecruzan y unen. El dominio político llevado a cabo por un pequeño sector social, es un hecho típico de la sociedad que se presenta, principalmente, en los municipios y ciudades del Antiguo Régimen ${ }^{2}$. De esta manera, a través de las diferentes formas de estudio en las que puede emprenderse el análisis de poder, así como, los organismos con los que se lleva a cabo, creemos útil averiguar diferentes matices vinculados con el conjunto de personas del que se conforma ${ }^{3}$.

1 Las tareas de campo realizadas sobre este trabajo han tenido lugar en el Archivo Municipal de Vinaròs [AMV] y en el Archivo Parroquial de Vinaròs [APV].

2 GIMENO SANFELIU, Ma. J. (1990): La oligarquía urbana de Castelló en el siglo XVIII. Castellón de la Plana, Ayuntamiento de Castellón. Gimeno Sanfeliu, Mª. J. (1998): Patrimonio, parentesco y poder. Castelló (XVI-XIX). Universitat Jaume I. Diputación de Castellón. Castellón, p. 165.

3 BERNABÉ GIL, D. (2001): "Insaculación, oligarquía e intervencionismo regio en la villa de Xixona (ss. XVI-XVII)". Revista de historia moderna. Anales de la universidad de Alicante. N. 19, pp. 79-122. 
A lo largo del siglo XVIII, el Ayuntamiento de Vinaròs significó un espacio fundamental de poder, idóneo para crear un entorno político característico de la zona, el cual con el paso de los años iría configurándose con individuos de diversas procedencias sociales. Por tanto, el análisis de esta corporación administrativa municipal nos permitiría vislumbrar la personalidad del poder municipal y los personajes que lo detentaron ${ }^{4}$.

De este modo, el objetivo principal de dicho apartado será estudiar la intervención, la importancia, el poder y el mantenimiento de éste, así como, de los grupos sociales que lo desempeñan a través de los diferentes empleos de gobierno en el periodo que nos ocupa nuestra investigación. Sin embargo, no debemos caer en la tentativa de delimitar a esta élite en su ámbito político únicamente. Pues, como bien apunta Aranda Pérez, aunque entendamos que los colectivos que conforman esa camarilla de poder local sean, básicamente, los oficios de gobierno municipales, para aproximarnos de la forma más ajustada posible al espacio social y político del municipio debemos ensanchar cuanto podamos el campo de la élite ${ }^{5}$. Así, en el momento en que nos disponemos a estudiar el ejercicio de poder local hemos de tener en cuenta también otras agrupaciones de individuos con evidente renombre, buen crédito y repercusión socioeconómica ${ }^{6}$, esto es, sujetos propios del comercio, del Santo Oficio, escribanos, empleados públicos que sirven a la Corona, doctores, abogados, entre otros?.

Se trata, por tanto, de un sector de la sociedad que sobresale, bien sea por su ejercicio político, por su actividad económica, comercial o administrativa, o bien por la acumulación de todas ellas, convirtiéndose en una clase dirigente con una diferenciación social e influjo palpables. Así pues, de igual manera que intuimos que el grupo de la sociedad vinarocense con mando, como los alcaldes y regidores, representan el colectivo con cotas más elevadas de poder e influjo en el núcleo urbano, debemos considerar

4 Véase anexo. Figuras 2-14.

5 ARANDA PÉREZ, F. J. (1991): "Prosopografía y particiones de bienes: una propuesta metodológica para el estudio de las oligarquías urbanas castellanas en la Edad Media". Cuadernos de Historia Moderna. N.12, pp. 259-276.

6 Este trabajo forma parte de una investigación más amplia, titulada "Las élites locales en el Vinaròs de la segunda mitad del siglo XVIII", de la cual saldrán nuevas publicaciones próximamente.

7 BERNABÉ GIL, D. (2001), op. cit., p. 93. 
que coexisten otros sujetos respetables en diferentes aspectos sin estar necesariamente vinculados al gobierno municipal de Vinaròs ${ }^{8}$.

En el núcleo urbano de Vinaròs, los cargos municipales que, establecida la Nueva Planta configuraron el corpus político para el gobierno y administración del municipio, es decir, alcaldes ordinarios, regidores, síndico procurador general y alcalde de hermandad, fueron todos elegidos y nombrados por el rey el 1 de enero de 1710, creándose así el primer ayuntamiento del término municipal de Vinaròs?. Las personas elegidas para desempeñar tales funciones de gobierno fueron seleccionadas a través de una lista de electores propuesta por la villa de Vinaròs. De dicha lista surgieron dos alcaldes ordinarios, cuatro regidores, un procurador general, dos alcaldes de Hermandad y, por último, un escribano para el Ayuntamiento de la villa, todos ellos aprobados por el "Excelentísimo Sr. D. Francisco Caetano Aragón, teniente general de los ejércitos de Su Majestad y comandante general de la ciudad y reino de Valencia"10. A medida que vayan pasando los años y creciendo las necesidades se irán creando nuevos puestos y cargos que servirán para continuar gestionando el funcionamiento del ayuntamiento borbónico de Vinaròs.

\subsection{Alcalde ordinario}

El primer alcalde que se nombró para la villa de Vinaròs fue Juan Bautista Febrer de la Torre, de condición noble, en el año $1710^{11}$. No obstante, bien entrado el siglo XVIII, tendrán la posibilidad de entrar en dicha lista de electores no solo aquellos de clase noble, sino también aquellos vecinos con cierta riqueza y patrimonio, supuestamente exigida a los de clase hidalga. De todas formas, vemos que no solo era el aspecto social un elemento importante, sino también el factor económico para acceder a este empleo municipal ${ }^{12}$.

8 Dentro del grupo de los comerciantes encontraremos extranjeros, concretamente, franceses, de los cuales hallamos personas de cierta influencia como los vicecónsules que residieron a lo largo del Setecientos en Vinaròs. AMV. "Relación del vecindario general de la villa de Vinaròs en el año 1754". Caja X. Exp.3.

9 Véase anexo. Figura 1.

10 AMV. Llibres del consell. Manos de Consejo y deliberaciones (1710-1713), caja 561, leg.3.

11 Ibídem. Caja 561. Leg.3. Acta de 1709-1710.

12 CUESTA MARTíNEZ, M. (1997): Oficios públicos y sociedad. Administración urbana y relaciones de poder en la Córdoba de finales del Antiguo Régimen. Universidad de Córdoba, Córdoba, p.358. 
Así pues, serán varios los alcaldes de otros estamentos sociales, pero con numerosas propiedades, los que accedan a las alcaldías. En el caso del núcleo urbano de Vinaròs, alcanzaron dicha judicatura gente adinerada, como los labradores Agustín Esteller de Pedro -alcalde en 1792- e lldefonso Miralles -alcalde en 1796-, ambos presentan gran cantidad de bienes en los padrones de riqueza de $1790^{13}$.

Por otro lado, la participación del estamento nobiliario en el ayuntamiento era de esperar. Pues, tal y como hemos comentado anteriormente, con los primeros cargos que se designan, observamos una predilección de "hijos Dalgo" -junto con el de los ciudadanos- para ocupar los cargos más notables de la estructura política y administrativa ${ }^{14}$. En cuanto al periodo que nos ocupa, destacarían dentro de este cargo miembros de familias de clase noble, por ejemplo, don Francisco Luís Julián ${ }^{15}$, nombrado alcalde en 1791. Por su parte, don Juan Bautista Febrer y Ferrán, cuya hidalguía ya le provenía de su padre, don Juan Bautista Febrer de la Torre ${ }^{16}$.

Si bien, la tónica de nombramientos de cargos concejiles podía haber significado, en un principio, un intento de aristocratización de esta institución, quedando representados los ayuntamientos de las principales ciudades en gran medida por una preeminente nobleza ${ }^{17}$, en las localidades como Vinaròs el absentismo de la clase noble que podemos observar en el poder municipal es palmario. Pues, únicamente los casos previamente nombrados son los que encontramos ejerciendo labores de gobierno municipal, en este caso, de alcaldía ${ }^{18}$.

13 AMV. "Relación del vecindario general de la villa de Vinaròs en el año 1754". Caja X, Exp.3, AMV. Grandes formatos. Padrón de riqueza. (1790).

14 Véase anexo. Figura 4.

15 Don Francisco Luís Julián, nombrado alcalde en 1791, según remitía y certificaba el escribano público del ayuntamiento de Vinaròs, Pedro Pons, el 5 de octubre en 1786, la existencia de la ejecutoría de nobleza declarada por la por la Real Audiencia de Zaragoza el 25 de mayo de 1778 a favor de don Joseph Julián y Oset -su padre-, probaba la hidalguía de este alcalde, así como, la de sus demás descendientes. AMV. Mano de órdenes y acuerdos [MOA]. Caja 9. Exp.1. (1783).

16 AMV, MOA, Caja 9. Exp.1, (1783).

17 GÓMEZ ZORRAQUINO, J.I. (2003): "Ni señores, ni campesinos-artesanos. El gobierno de los ciudadanos en Aragón". Burgueses o ciudadanos en la España moderna. N.6, pp. 384-385.

18 Véase anexo. Figura 4. 


\subsection{Alcalde de hermandad}

Según Cuesta Martínez, los alcaldes de la hermandad se comprometían a inspeccionar los campos y revisar todos los límites de su circunscripción con el objetivo de mantener bienes y personas, así como, la actividad comercial contra el bandolerismo ${ }^{19}$.

Según la documentación que hemos hallado aparecen escasos nombramientos de este cargo municipal y sin especificar si los elegidos pertenecían al estado noble o al estado llano en Vinaròs. Sin embargo, encontramos el caso de Joseph Gombau de Paula, cuyo nombramiento se publicó el 21 de enero de $1766^{20}$, cargo que, como era de costumbre, debía prestar juramento en la Iglesia Parroquial de la villa de Vinaròs -junto con los demás empleados elegidos nuevos en el gobierno municipal- de sus cargos y cumplir con sus obligaciones.

\subsection{Regidores}

Según establecía la norma castellana los regidores habían de ser oriundos del mismo núcleo urbano al que servían o estar empadronados en él ${ }^{21}$. Por ello, la mayoría de los individuos que desempeñaron este oficio en la villa de Vinaròs poseían esta condición. Además, dicho cargo era de carácter vitalicio, es decir, que aquel que lo obtenía lo ocupaba hasta el fin de sus días. Un ejemplo de estas características lo constituía Tomás Agustín Chaler, regidor cuarto en la villa de Vinaròs en 1793, quien tras su fallecimiento fue sustituido por el labrador Francisco Doménech, nombrado para este puesto el 17 de marzo de $1793^{22}$.

Por lo que respecta al acceso de dicho empleo municipal, los regidores de Vinaròs que conformaron el primer ayuntamiento borbónico ${ }^{23}$, tras la contienda de sucesión, fueron elegidos y nombrados el 1 de enero de $1710^{24}$. Una vez las primeras vacantes comenzaran a originarse, estos puestos de gobierno se irían cubriendo, aunque existían otras formas de ocupar dichas

19 CUESTA MARTíNEZ, M. (1997), Op. Cit., p. 382.

20 AMV, MOA, (1766). Caja 7. Exp.8.

21 Novísima Recopilación de las Leyes de España, libro VII, título V, ley I. Madrid, 1976.

22 AMV. MOA. (1793-1794). Caja 9. Exp.11. F.35.

23 Véase anexo. Figura 1.

24 AMV. Llibres del consell. Manos de Consejo y deliberaciones. (1710-1713). Caja 561. Leg.3. Acta de 1709-1710. 
plazas disponibles, como la herencia o el traspaso, además de la compra de regidurías perpetuas ${ }^{25}$.

Los regidores debían acudir a los cabildos ordinarios que tenían lugar en los salones de plenos de las casas municipales, al menos, dos veces a la semana, y estudiar las comisiones concertadas en el cabildo. Además de esta indispensable responsabilidad, los regidores vinarocenses también participaban en temas relacionados con el comercio de abastos, la sanidad pública, el control de la producción de los gremios y, finalmente, se ocupaban -al igual que los ediles de la ciudad de Alicante ${ }^{26}$ - del recaudo de las rentas reales de la administración.

Respecto a la edad en la que las personas elegidas en Vinaròs para este cargo podían conseguir la regiduría, parece complejo conocerla según la documentación que poseemos, dado que estos datos no aparecen en las actas de ayuntamiento, ni en los libros de órdenes y acuerdos, ni tampoco en los libros del consejo que hemos consultado. Si bien, afirma Irles Vicente ${ }^{27}$ que la edad mínima en que los regidores valencianos podían acceder a este puesto era a los 25 años. En este momento cabe decir que algunos de los que la obtuvieron, bien por que se hallaban en unas facultades físicas lamentables, o bien por vejez, se vieron obligados a rechazarlas. Ante esta situación existían formas de rehusar el puesto: el traspaso y/o la renuncia, llevadas a cabo por aquellos que tenían la intención de dejar el puesto por hallarse incapacitados para continuar ejerciéndolo.

En el caso de los regidores vinarocenses, de la primera no tenemos constancia de ningún suceso según la documentación que disponemos. No obstante, de la segunda creemos que el ejemplo de los regidores Juan Bautista Lasala (Lassala) y Francisco Reverter ${ }^{28}$ puede ser ilustrativo en este aspecto, pues debido a presentar "graves achaques [...] y avanzada edad", se vieron forzados a solicitar la renuncia como regidores.

\subsection{Perfil profesional de los regidores}

Respecto a las profesiones más comunes entre los regidores vinarocenses, encontramos un abanico variado, abarcando labradores, marineros, abo-

25 IRLES VICENTE, M.C. (1991): Los regidores valencianos. Perfil sociológico de una élite de poder. Universidad de Alicante, pp. 192-193.

26 GIMÉNEZ LÓPEZ, E. (1990): "El municipio borbónico". Historia de la ciudad de Alicante. Tomo III: Historia Moderna. Universidad de Alicante, p. 238.

27 IRLES VICENTE, M.C. (1991), op. cit., p. 199.

28 AMV. MOA (1783). Caja 9. Exp.1. 
gados, negociantes y tratantes, cereros, hacendados, soldados, escribanos, plateros y médicos ${ }^{29}$.

Parece evidente la discreción y silencio que a veces trata la documentación a las comunidades que quedaban excluidas del marco urbano, como eran los labradores y que, por tanto, dificulta indagar en algunos elementos y estilos de vida de la sociedad agraria ${ }^{30}$. Empero, la documentación que se ha mantenido y a la que hemos podido acceder, nos ha permitido atisbar que una parte de la colectividad agraria prosperó hasta alcanzar cotas de poder en el gobierno del municipio, es decir, como regidores del ayuntamiento. Es, por ejemplo, el caso de alguno de ellos que incluso consiguió mantenerse y promocionarse en el poder municipal con el paso del tiempo: Ildefonso Miralles aparece en los Libros de las Manos de órdenes y acuerdos como lugarteniente de alcalde en 1763, como alcalde de monte en 1791, accediendo antes a regidor tercero y segundo en 1767 y 1783 , respectivamente, para después conseguir la alcaldía en $1796^{31}$. Ejemplos de este tipo son los que certifican las facultades supuestamente económicas y de prestigio social que fueron adquiriendo con fuerza el grupo de los labradores en el Vinaròs del Setecientos.

Otros de los oficios destacables entre los regidores sería el de doctores y abogados, quienes, en Vinaròs, se encontraban ocupando el cargo de regidor primero (a veces designado mayor o decano) como es el caso del Dr. Pedro Antonio Cruz en 1763 y/o el Dr. Antonio Tarragó en 1764. Ambos individuos ascendieron en el ayuntamiento años más tarde, llegando a ocupar la alcaldía en 1776 y 1790, respectivamente ${ }^{32}$.

Otra forma que permitió afianzar el puesto de regidor fue a través de las estrategias matrimoniales entre familias que frecuentaban las regidurías a lo largo del siglo XVIII en el municipio de Vinaròs. Se trataba, pues, de un matrimonio endogámico de clase, dado que los enlaces se producían entre

29 Véase anexo. Figuras 5-8.

30 ASENJO GONZÁLEZ, M. (1981): "Labradores ricos: nacimiento de una oligarquía rural en la Segovia del siglo XV". La España Medieval, 4, pp. 63-85.

31 AMV. MOA. (1763). Caja 7. Exp.6. AMV. MOA. (1783). Caja 9. Exp.1. AMV. Caja 9. Exp.9. Manos de órdenes y acuerdos. (1791). AMV. MOA. (1763). Caja 9. Exp.13. Véase anexo. Figuras 4, 6, 7, 9, 10 y 11.

32 AMV. MOA. (1763). Caja 7. Exp.6. AMV. MOA (1764). Caja 7. Exp.7. AMV. MOA. (1763). Caja 8. Exp.3. AMV. MOA. (1790). Exp.8. Véase anexo. Figuras 4-8. 
sujetos de un mismo sector social, considerados como iguales. Un caso representativo sería la alianza producida entre las familias Escrivano y Morales $^{33}$.

\subsection{Síndico personero y diputados del común}

Tras las revueltas acaecidas con el motín de Esquilache en 1766 se llevará a cabo la creación de los cargos de diputados y síndicos personeros del común, aprobándose una nueva normativa que completaba la transformación municipal de Carlos III. La reforma fue conducida a la adhesión de otros oficios que contribuyesen a solucionar la desazón del pueblo ${ }^{34}$ o del común como aparece en la documentación. Los diputados y síndicos personeros del común quedaron establecidos en Vinaròs a través del comunicado emitido por Frey don Joseph Tomás Garcés de Marcilla, el 20 de noviembre de 1766. En él se provenía que se debían elegir y nombrar anualmente los diputados y personeros del común en cada pueblo ${ }^{35}$. Asimismo, el 30 de abril del mismo año se llevaron a cabo las elecciones y nombramientos de los sujetos que desarrollarían las funciones de dichos oficios en la villa de Vinaròs.

El sistema de nombramiento ${ }^{36}$ de un diputado y un síndico personero del común en Vinaròs se realizaba a través de la elección de dos de los veinticuatro electores que se proponían entre todos los barrios (de cada barrio eran propuestas dos personas) que componían el núcleo urbano ${ }^{37}$. Los primeros cargos, en 1766, fueron otorgados al doctor Francisco Esteller (Síndico personero del común) y a Francisco Reverter (Diputado del común $1^{\circ}$ ) y Vicente Esteller (Diputado del común $\left.2^{\circ}\right)^{38}$. Ninguno de los tres elegidos pertenecía anteriormente al gobierno municipal de Vinaròs, ni tampoco consta la

33 APV. Libro de matrimonios, volumen IV. 1746-1775. Libro de matrimonios, volumen V. 17761795. Libro de bautismos, volumen XI. 1780-1786. Véase anexo. Figura 19.

34 AMORÓS VIDAL, F. (2002): "El Síndico personero: la voz del común". En III Congreso Turístico Cultural del Valle de Ricote, pp.405-425.

35 AMV. MOA. (1766). Caja 7. Exp.8.

36 Los nombramientos de estos cargos se encuentran, normalmente, bastante esparcidos -o incluso no aparecen- en las actas de ayuntamiento y otra documentación que hemos analizado. No obstante, tenemos constancia del ejercicio de estos individuos en los cargos de diputados y personero del común, dado que se hallan como signatarios o firmantes en los diferentes documentos que, según las funciones de su cargo, tienen participación.

37 AMV. MOA. (1783-1784). Caja 9. Exp.2.

38 AMV. MOA. (1766). Caja 7. Exp.8. 
presencia de éstos en las actas que hemos analizado, lo cual corrobora el hecho que afirma Molas Ribalta de que la procedencia de los titulares de estos nuevos cargos era más extensa, dando cabida a los maestros de los gremios más relevantes ${ }^{39}$.

Respecto al ejercicio de los diputados y personeros del común en Vinaròs, éstos actuaban en todas las materias relativas a los abastos, teniendo la posibilidad de acudir a los cabildos municipales y tener voto absoluto en la Junta de Propios y Arbitrios en todos los asuntos que se presuponía discutir sobre la recaudación, el gobierno y la administración en el municipio de Vinaròs ${ }^{40}$. Por tanto, la funciones de estos empleados que representaban la voz del pueblo, se basaban en la inspección de los abastecimientos que tanta inquietud despertaba entre el pueblo, pero también se ocupaban de controlar los mercados públicos; en tal sentido merece destacar una queja expuesta por los pescadores de la villa de Vinaròs en la que solicitan vigilar que no se cometiera fraude en los pesos y en las medidas de la venta de la boga, puesto que la libra se estaba vendiendo a más precio del establecido $y$ aforado ${ }^{4}$.

Si bien eran evidentes las funciones que estos nuevos cargos debían desarrollar, se hicieron manifiestas también las que no podían desempeñar: quedaba prohibido que manejaran asuntos propios de los tesoreros de ejércitos y/o empleados de las Rentas Reales, debido a la perturbación que la Administración de Rentas había sufrido por este grupo en otros pueblos del reino. Así se lo comunicaba el escribano vinarocense, Juan Bautista Borrell al que por aquel entonces era el corregidor de Peñíscola, don Joseph Sanjust ${ }^{42}$.

El desconcierto se produciría quizá, conforme apunta Cuesta Martínez ${ }^{43}$, a través de la problemática con la que se encontraría este reciente cargo, esto es, la presencia del procurador síndico general. Principalmente el cometido de ambos coincide, es decir, focalizar la atención en las necesidades del común. Así ocurre en febrero de 1783 cuando el síndico procurador general y el síndico personero de la villa de Vinaròs desarrollaron, conjuntamente, una protesta hacia los regidores del ayuntamiento mostrando disconformidad por la concesión de tres solares para construir y establecer

39 MOLAS RIBALTA, P. (2004): "Diputats i síndics a l'ajuntament borbònic de Barcelona (17601808)". Revista de Dret Històric Català. Societat Catalana d'Estudis Jurídics. N. 4, pp.11-27.

40 AMV. MOA. (1766). Caja 7. Exp.8.

41 Ibídem. Caja 7. Exp.8.

42 Ibídem. Caja 7. Exp.8.

43 CUESTA MARTíNEZ, M. (1997), Op. Cit., p. 349. 
fábricas y almacenes en las peñas junto al varadero y embarcadero del barrio de Santa Magdalena. Desaprobaban los síndicos esta pretensión de los regidores, dado que quitaría espacio y holgura para el desembarco de la sal, así como, para los embarques de vino, que necesitarían toda la extensión de dicho espacio para poder llevar a cabo tal tarea. Además de impedir el suministro de sal, dichos establecimientos imposibilitaban la defensa de la playa nueva de Santa Magdalena. Por ello, "protestaban una, dos, tres y más veces, y las que derecho sea" contra el propósito de los regidores porque consideraban que su función era la de evitar los periuicios al común ${ }^{44}$.

En cuanto a los elegidos y electos, a pesar de tratarse de una medida que trataba de dar voz en los ayuntamientos al pueblo, este cargo permanecería expuesto a los desacuerdos que surgieran tanto por el entendimiento de la norma como por las dificultades de mentalidad ante los cargos nuevos. Fundamentalmente, los elegidos podían ser cualquiera de entre los vecinos contribuyentes. No obstante llama la atención cuando lo que se trata de investigar son las personas elegidas para dicho cargo, teniendo en cuenta sus apellidos y su nivel económico y social ${ }^{45}$. En este punto, es necesario observar quiénes están en las listas de lectores y quienes permanecen en las mismas a lo largo de los años.

Del conjunto de diputados y síndicos personeros del común que hemos podido recopilar, era frecuente hallar la presencia de clanes familiares ya relacionados con el poder municipal; nos referimos a los Piñol. Esta saga familiar de plateros aparece en diversas ocasiones en las listas de elección de diputados y síndicos personeros del común, pero también en el gobierno municipal de Vinaròs. Pues, encontramos la figura de Bautista Piñol presente en las primeras listas que se llevaron a cabo para la elección de los diputados y personero el 30 de abril de 1766. Aunque no resultara elegido, aparece como síndico procurador general en los años 1760, 1773, 1777, y como regidor segundo en $1767^{46}$. También, otros Piñol -a través de las listas- anhelarían alcanzar alguno de los puestos representativos del común; Pascual Piñol (en 1766), Antonio Piñol (en 1784 y 1793), Joaquín Piñol (en 1793) y Carlos Piñol, lográndolo en $1798^{47}$.

44 AMV. MOA. (1783). Caja 9. Exp.1.

45 CUESTA MARTíNEZ, M. (1997), op. cit., p. 350.

46 AMV. MOA (1767). Caja 7. Exp.9. AMV. MOA. (1760). Caja 7. Exp.4. AMV. MOA. (1773). Caja 8. Exp.1. AMV. MOA. (1777). Caja 8. Exp.4. Véase anexo. Figuras 6 y 9.

47 Carlos Piñol fue, además, alcalde y juez ordinario de la villa de Vinaròs en 1764 . Véase anexo. Figura 4 y 14. 
Era, por tanto, corriente encontrar en las listas electorales miembros que ya habían ejercido algún cargo de poder en el Ayuntamiento y/o individuos que ocuparon cargos dentro del mismo después de haber sido diputados o personeros del común. Como ejemplo de estos electores vinculados al poder gubernamental de la villa de Vinaròs que se presentaron como posibles diputados y personeros del común citaremos a Bautista Miralles y Roldán (valedor en el ayuntamiento de 1755), Vicente Doménech (regidor $2^{\circ}$ en 1769), Tomás Forner (regidor $4^{\circ}$ en 1755), Bautista García (regidor $3^{\circ}$ en 1764; regidor decano en 1778; lugarteniente de alcalde en 1796), Bautista Dufor (regidor decano en 1796 y diputado del común en 1782) y Cristóbal Agramunt (regidor $4^{\circ}$ en 1768; regidor $2^{\circ}$ en 1781 y 1782 , alcalde de monte $1^{\circ}$ en 1777$)^{48}$.

De entre los diputados y síndicos personeros elegidos, tres de ellos tenían el título de escribanos públicos del Ayuntamiento y ejercieron como tales en la villa de Vinaròs. En este caso, mencionaremos a Francisco Reverter (diputado del común entre 1766-1767), Francisco Reguart (diputado del común en 1781) y Pedro Barragán (diputado del común en 1793). La influencia de alguno de estos individuos era tal que incluso lograron una regiduría; nos referimos a Francisco Reguart, quien habiendo ejercido anteriormente como síndico procurador general en 1763, ocupará el cargo de regidor del Ayuntamiento en $1767,1773,1783^{49}$.

También, hallamos diputados y personeros que disfrutaban del grado de doctores: el Dr. Francico Esteller y el Dr. Antonio Tarragó. Uno de ellos, el Dr. Antonio Tarragó, aparece en las actas de ayuntamiento ocupando cargos como regidor decano (1764) y como alcalde (1773 y 1790$)^{50}$.

De la misma manera, no está de más la presencia de emigrantes o sujetos de ascendencia extranjera presentes en los cargos de diputados y síndicos personero del común. En este caso podemos nombrar al menos dos casos, a saber, Francisco Bonafont y la de Juan Guilheume. Ambos sujetos pertenecen a familias de comerciantes de origen francés. Bonafont ocupará el cargo de síndico personero del común en 1784 mientras que Guilheume

48 AMV. MOA (1755). Caja 6. Exp.19. AMV. MOA (1769). Caja 7. Exp.13. MOA (1778). Caja 8. Exp.5. MOA (1782), Caja 8. Exp.7. MOA (1796). Caja 9. Exp.13. MOA (1777). Caja 8. Exp.4. Véase anexo. Figura 2, 6, 7, 8, 12 y 14.

49 AMV. MOA (1767). Caja 7. Exp.9. AMV. MOA (1773). Caja 8. Exp.1. AMV. MOA (1783). Caja 9. Exp.1. AMV. MOA. (1763). Caja 7. Exp.6. Véase anexo. Figuras 5-9.

50 AMV. MOA. (1764). Caja. 7. Exp.7. AMV. MOA. (1773). Caja. 8. Exp.1. AMV. MOA (1790). Caja. 9. Exp.8. Véase anexo. Figuras 4,12 y 14. 
lo hará en calidad de diputado en el mismo año ${ }^{51}$. La presencia de comerciantes dentro de este grupo puede que se deba, como hemos comentado más arriba, a que los diputados y síndicos personeros también se ocupaban de controlar los mercados públicos, momento en que el libre mercado y afluencia se presentaban como el método más propicio para garantizar el abastecimiento 52 .

Por último, cabe señalar la ausencia de los alcaldes de Barrio en el Ayuntamiento municipal vinarocense en el siglo XVIII. A pesar de ser otro de los empleos concejiles creados con el reformismo municipal de 1766, no aparecen en la segunda mitad del siglo XVIII en Vinaròs. No obstante, sí tenemos constancia de su nombramiento a principios del siglo XIX, concretamente en $1818^{53}$.

Inicialmente, los alcaldes de Barrio y de Cuartel se establecieron en Madrid en 1768. Más tarde fueron extendiéndose por el resto del territorio, en algunos lugares, como en Córdoba, no se crearán hasta $1812^{54}$. Por ejemplo, en el Ayuntamiento castellonense, tuvieron que esperar hasta 1786. Eran elegidos anualmente cuatro alcaldes de Barrio, dos correspondían al Cuartel del Corregidor y los otros dos al Cuartel del Alcalde Mayor ${ }^{55}$.

\subsection{Otros empleos municipales del Ayuntamiento de Vinaròs}

La gama de oficios y cargos entre los diferentes empleados del gobierno del núcleo de Vinaròs era bastante limitado y poco prolífera en lo que al número de cargos y personas se refiere. La documentación de las mismas actas y sesiones de ayuntamiento no se ha conservado en su totalidad, por lo que desconocemos en gran medida varios de los cargos que se produjeron, así como, las personas que los desempeñaron.

No obstante, encontramos ayuntamientos de algunos años en los que éstos aparecen -en la medida de lo posible- bastante completos ${ }^{56}$.

51 Véase anexo. Figuras 12 y 14.

52 AMORÓS VIDAL, F. (2002), op. cit., p. 7.

53 AMV. Nombramiento de Alcaldes de Barrio. (1818). Caja 12. Exp.9.

54 CUESTA MARTíNEZ, M. (1997), op. cit., pp. 370-375.

55 FERNÁNDEZ NADAL, C.M. (2003): El Corregimiento de Castellón en época de Carlos III: entre la continuidad y la reforma. Ayuntamiento de Castellón, Castellón, pp. 30 y 175 (aparecen reseñados los alcaldes de Barrio durante el reinado de Carlos III, entre 1786-1788).

56 Véase anexo. Figura 3. 
No solo aparecen los cargos principales, sino otros de carácter más secundario pero que también son interesantes de mencionar. Aunque carecemos de cantidades totales de la representatividad de estos cargos en el Ayuntamiento vinarocense hallamos, por ejemplo, la figura del predicador de la Cuaresma el cual estaría representado por un eclesiástico que se encargaría de reproducir las predicaciones en este periodo del año. Igualmente, observamos que aparecen los cargos de pregonero y el de morbero. El primero se encargaría de anunciar públicamente los acuerdos de ámbito común que concernían a todos los vecinos de Vinaròs. Por su parte, el segundo tenía la función de avisar sobre las embarcaciones que llegaban a la orilla del mar, controlando su procedencia y las patentes que traían ${ }^{57}$. Otro oficio de carácter popular y de carga concejil sería el de dulzainero, encargado de tocar en todas las funciones de la villa, pagándole la cantidad de 71 libras anuales ${ }^{58}$.

También, hallamos cargos como el de lugarteniente de alcalde que no gozan de un protagonismo tan dominante como los demás empleos municipales. No obstante, sabemos que se trataba de un cargo anual y que era conocido como alguacil mayor en la villa de Vinaròs ${ }^{59}$.

Igualmente, existieron cargos de ámbito religioso con los que contaría el Ayuntamiento vinarocense, como era el de sacristán de la Virgen, encargado, normalmente, de estar al servicio del cuidado y el aseo de la sacristía. Este puesto podía ser desarrollado por varias personas. En Vinaròs observamos que en 1784 eran dos los encargados de mantenerla: Joaquín Sisarch y Francisco Costa. También, sobresaldrían otros oficios de carácter más administrativo y recaudatorio, como son el de administrador del arriendo de la nieve, el del arriendo de abasto y carnes y el receptor de la Bula ${ }^{60}$.

Por último, la presencia de los alcaldes de monte era bastante frecuente en todos los ayuntamientos que hemos podido reconstruir. El motivo de este particular cargo vendría justificado por tratarse de una población fundamentalmente agraria, con grandes extensiones de campo que necesitarían ser controlados y guardados ${ }^{61}$. Un cargo análogo al alcalde de monte apa-

57 AMV. MOA (1757). Caja 7. Exp.1.

58 Véase anexo. Figura 3.

59 AMV. Índice general de los censos que la villa corresponde y están continuados en el libro nuevo. (1774). Caja 244. Véase anexo. Figura 10.

60 Véase anexo. Figura 3.

61 Véase anexo. Figura 11. 
recería en el Ayuntamiento municipal de Castellón a lo largo del siglo XVIII, esto es, el guarda de campo. También, son característicos del municipio castellonense los cequieros, debido a la cantidad de acequias que recorrían el término ${ }^{62}$.

\subsection{Las escribanías}

Pese a que el principal propósito de nuestro trabajo sea estudiar la hegemonía a nivel municipal de un restringido grupo social, esto es, de la oligarquía urbana de Vinaròs en el Setecientos, consideramos que sería interesante cercar nuestro estudio más allá del poder municipal, abarcando otro colectivo conectado y relacionado continuamente con las élites sociales, es decir, el de los escribanos. Como afirma Extremera Extremera ${ }^{63}$, la persona del escribano representa una figura clave debido a su función burocrática de interceder en el poder, transmitiendo la información entre la población iletrada y la población más opulenta y representativa a nivel municipal. Este gremio influyente en la sociedad, podía disfrutar de una buena estimación, privilegio y deferencia social ${ }^{64}$, al igual que lo hacían los diferentes miembros que configuraban el espacio de poder municipal.

Diversos tipos de escribanos realizaban sus actividades en Vinaròs en el siglo XVIII. Un ejemplo del tipo de escribanía de Marina lo encontramos desarrollado por Francisco Reverter, escribano público en la villa de Vinaròs. Reverter fue titulado por el Colegio de Escribanos de la ciudad de Valencia el 4 de diciembre de 1739, y nombrado por don Francisco Barrero, miembro del Concejo de Su Majestad. Además, ejercía el oficio de escribano del Número y Juzgados en el mismo núcleo urbano de Vinaròs, otorgado el 4 de enero de 1745 por don Gaspar Domingo Prima, dueño de dicha escribanía ${ }^{65}$. Las funciones que debía ejercer un escribano de esta tipología eran transcribir actos de índole judicial y/o extrajudicial, así como, aprobar las escrituras de los acuerdos que se llevaran a cabo entre individuos en los que intercediera como notario. Sus funciones estaban destinadas a llevarse a cabo en la misma circunscripción para el que fueron designados ${ }^{66}$. Pasos

62 FERNÁNDEZ NADAL, C. M. (2003), Op. Cit., pp. 32, 153-158.

63 Extremera Extremera, M. A. (2001): "Los escribanos de Castilla en la Edad Moderna. Nuevas Líneas de Investigación". Chronica Nova, 28, pp. 160-161.

64 GÓMEZ NAVARRO, S. (2001): La letra y el espíritu de la letra: notario, formulario notarial e historia. Universidad de Córdoba, p. 2.

65 AMV. MOA (1782). Caja. 8. Exp.7. También serían nombrados escribanos de juzgados por el noble don Gaspar Domingo Prima: Agustín Sabater y Pedro Barragán.

66 CUeSTA MARTíNeZ, M. (1997), Op. Cit., p. 410. 
similares a los de Reverter seguirá Pedro Barragán, nombrado escribano público, del Número y Juzgados el 12 de noviembre de 1763 por el marqués de Angulo y lugarteniente general de la militar orden de Nuestra Señora de Montesa ${ }^{67}$.

No obstante, la importancia e influencia de estos individuos es tal que no solo pueden hallarse realmente ligados a la élite de poder sino que también pueden llegar a formar parte de ella, es el caso de escribanos, tales como Agustín Sabater, Francisco Reguart, y/o Nicolás Doménech. Esta estrecha relación y convivencia con la autoridad puede hacer que se vean compaginando sus cometidos del ámbito administrativo con los de carácter político, ejerciendo algún cargo de poder en el Ayuntamiento.

Francisco Reguart, escribano de la Orden de Nuestra Señora de Montesa aparece ya en las actas de ayuntamiento de 1763 designado para ejercer el cargo de síndico procurador general. Más tarde, en 1767 se estrenaría en las regidurías, concretamente, en la de regidor decano, cargo que desarrollará también en 1773 y $1783^{68}$. Reguart fue nombrado escribano para todas las villas y lugares de la Orden de Nuestra Señora de Montesa por el lugarteniente general de la orden, el marqués de Angulo, el 13 de noviembre de 1757, destinándole a ejercer sus funciones en el Ayuntamiento de Vinaròs el 20 de noviembre del mismo año69.

Por su parte, Agustín Sabater, natural y vecino de Vinaròs, obtuvo el nombramiento de escribano Real para el Reino de Valencia ${ }^{70}$ por el Real Colegio de la ciudad Valencia. Según la documentación que hemos examinado, dicho título fue dado por el rey, Fernando VI, el 5 de diciembre de 1754, permitiéndole actuar en todas las causas civiles y criminales como escribano de los juzgados ordinarios de la villa de Vinaròs, a partir del 20 de septiembre de 1761. De igual manera, Sabater logró ocupar la escribanía del número, cuyo cometido se basaba en funciones burocráticas y de índole notarial, acreditando y atestiguando todas las actas y documentos públicos con los que trataba ${ }^{71}$. Sabater también resulta ser un buen ejemplo de ese

67 AMV. MOA Caja 8. Exp.8.

68 AMV. MOA (1763). Caja 7. Exp.6. AMV. MOA (1767). Caja 7. Exp.10. AMV. MOA (1773). Caja 8. Exp.1.

69 AMV. MOA (1782). Caja 8. Exp.7.

70 Ibídem. Caja 8. Exp.7.

71 CÓZAR GUTIÉRREZ, R. (2009): «"De lo que yo el infrascrito escribano doy fe". Los escribanos de la villa de Albacete durante el siglo XVIII». Revista de historia moderna, 28, p. 275. 
tipo de escribanos que complementarían sus funciones propias de un fedatario público con las internas en el gobierno vinarocense, ocupando cargos como el de regidor decano en el Ayuntamiento de $1786^{72}$.

Otro ejemplo de entre los escribanos que desempeñaron su papel en las esferas de poder de Vinaròs sería el de Nicolás Doménech; escribano de la militar orden de Nuestra Señora de Montesa, nombrado el 2 de julio de 1771 por el marqués de Angulo para ejercer sus funciones de escribano público del Ayuntamiento de Vinaròs. Asimismo, llegó a realizar las prácticas de escribano en el despacho de Francisco Reverter "con aplicación a cuantas diligencias han ocurrido"73. Doménech, además de cumplir con su plaza de escribano durante más veinte años, supo compatibilizarla con el oficio de alcalde ordinario con el que fue asignado en $1793^{74}$, así como, con el de regidor decano en $1797^{75}$.

Como vemos era bastante frecuente la presencia del escribano en los diferentes espacios del poder municipal. Encontramos escribanos que si bien no participaban de manera interna en el gobierno vinarocense, sí se encontraban ligados y vinculados a los miembros que componían el ayuntamiento. El escribano público Pedro Pons, cuyo padre, Damián Pons y Roger cubrió diferentes puestos en el ayuntamiento como juez contador en 1755; regidor decano en 1777 y alcalde en 1760. También, su tío Josef Pons y Roger, familiar del Santo Oficio, desempeñó las funciones de regidor decano en 1790 y las de alcalde en $1783^{76}$. Pons, como escribano público del Ayuntamiento de Vinaròs -según Cózar Guitiérrez ${ }^{77}$, uno de los cargos profesionales más relevantes de este grupo en la cúpula municipal- fue nombrado escribano de la militar orden de Nuestra Señora de Montesa el 17 de julio de 1773 por el lugarteniente general, el marqués de Angulo. Igualmente, ejercía la escribanía de marina para la que fue nombrado por don Alonso de Venero, ministro principal, en julio de $1787^{78}$.

Por otro lado, también podían ejercer los escribanos del Reino en la villa de Vinaròs, como es el caso de Joseph Antonio Peñarroja quien, a parte de

72 AMV. MOA (1786). Caja 9. Exp.5. Véase anexo. Figura 5.

73 AMV. MOA (1769). Caja 7. Exp.13.

74 AMV. MOA (1793). Caja 9. Exp.11. Véase anexo. Figura 4.

75 AMV. MOA (1797). Caja 9. Exp.19. Véase anexo. Figuras 5-8.

76 AMV. MOA (1783). Caja 9. Exp.1. AMV. MOA (1790). Caja 9. Exp.8. AMV. MOA (1755). Caja 6. Exp.19. AMV. MOA (1777). Caja 8. Exp.4. AMV. MOA (1760). Caja 7. Exp.4.

77 CÓZAR GUTIÉRREZ, R. (2009), Op. Cit., pp. 282-283.

78 AMV. MOA (1790). Caja 9. Exp.8. 
ocupar esta escribanía, desarrolló en Valencia la de escribano de Salinas ${ }^{79}$. Por último, encontramos a Joaquín Gil y a Juan Bautista Mirán quienes serán nombrados con el oficio de escribano Real y notario público ${ }^{80}$.

\section{CONFIGURACIÓN DE LA OLGARQUía URBANA POR VÍAS ECONÓMICAS Y COMERCIALES}

A continuación, pretendemos averiguar y rescatar del anonimato a los comerciantes que formaban parte de esa oligarquía urbana, intentando identificar la forma de proceder en el ámbito social, económico y político de unos determinados sujetos, siendo muchos de ellos extranjeros, en el núcleo urbano de Vinaròs. Exponemos, pues, un análisis tan detallado como nos permite la documentación acerca de los miembros y familias que configurarían esa élite mercante de Vinaròs a partir de la segunda mitad del siglo XVIII.

\subsection{Los comerciantes en Vinaròs}

Como hemos analizado previamente, la villa de Vinaròs se ha caracterizado, en su mayor parte, por su esencia agraria y marítima. No obstante, según la documentación consultada, existía una inclinación hacia el comercio por parte de sus habitantes, debido a las ventajas geográficas y portuarias que presenta dicha urbe. Como grupo social, los comerciantes de Vinaròs significaron un $3,2 \%$ de los vecinos de la urbe a mediados del Setecientos ${ }^{81}$. Según el padrón de 1754, la mitad de éstos eran oriundos de Vinaròs, y la otra mitad eran procedentes de naciones europeas como Francia e Irlanda. En cuanto a su distribución en la urbe, había una evidente tendencia por parte de esta élite comercial a residir en la calle San Jaime, seguida de cerca por el barrio del Ángel y el de San Antonio. Las calles de Santa María Magdalena, los Médicos y San Antonio eran otros de los espacios urbanos habitados por este grupo social. Finalmente, un porcentaje muy reducido se

79 Ibídem. Caja 9. Exp.8.

80 Joaquín Gil consiguió su título el 23 de mayo de 1786, llegando a ejercer la escribanía de rentas por nombramiento de la Dirección General el 24 de diciembre de 1786 Mientras que Juan Bautista Mirán obtendría su título de escribano el 24 de febrero de 1790. AMV. MOA (1790). Caja 9. Exp.8.

81 En base al censo de 1754, elaborado por el duque de Caylus, Vinaròs contaba con 785 vecinos de los cuales 25 -un 3,2\% del vecindario- se dedicaban al comercio. Curiosamente, casi la mitad de estos comerciantes eran de origen extranjero. Por tanto, la mayoría de los extranjeros los consideramos mayoría comercial con la excepción de Juan Legeume (labrador) y Antonio Vidal (calderero). AMV. "Relación del vecindario general de la villa de Vinaròs en el año 1754". Caja X. Exp.3. Véase anexo. Figura 18. 
asentaba en los barrios del Rosario, San Vicente y/o la Plaza de la Iglesia ${ }^{82}$. Según la documentación consultada, los mercaderes establecidos en Vinaròs en la primera mitad del siglo XVIII fueron, principalmente, comerciantes irlandeses y franceses ${ }^{83}$. A éstos se sumarían, ya a finales del siglo XVIII, comerciantes genoveses, napolitanos y malteses ${ }^{84}$. Estas colonias extranjeras inmigradas en Vinaròs entre la segunda mitad del siglo XVIII y finales de mismo, encontraron en la actividad comercial su principal fuente de ingresos. No era insólita la presencia de población foránea en Vinaròs, dado que el término y su embarcadero era un punto clave de intercambio de mercancías en el Mediterráneo.

Así pues, dentro de la población vinarocense de mediados del siglo XVIII, nos encontramos con personas de orígenes diversos, como genoveses, malteses, napolitanos, franceses e irlandeses. Serían estas dos últimas comunidades extranjeras las más visibles y asentadas en la villa de Vinaròs, llegando a adquirir una posición social influyente dentro de la élite comercial que les permitiría, incluso, desempeñar a algunos de ellos cargos de influencia en el poder político de Vinaròs ${ }^{85}$.

Por lo que respecta al comportamiento de la élite comercial en el Vinaròs del Setecientos, vemos su integración representada por un 19\% del total de la clase pudiente. De entre los casos que hemos hallado, un 7\% de esta clase acomodada serían propietarios de tiendas (botigueros); un $5 \%$ tratantes; un $6 \%$ comerciantes y un $1 \%$ correspondería a la vertiente de los negociantes. Así pues, parece conveniente matizar en este momento las diferencias que podían encontrarse entre los tipos de trabajos relacionados con el comercio. Por un lado, existían los grandes comerciantes -que significarían un grupo más pequeño- de entre los que podríamos destacar los negociantes y tratantes, que comercializaban no solo a nivel nacional sino también internacional, llegando a reunir importantes fortunas y propiedades que les permitieron disfrutar de un status socioeconómico privilegiado ${ }^{86}$.

82 AMV. MOA (1798). Caja 9. Exp.14.

83 Véase anexo. Figura 19.

84 Véase anexo. Figura 16.

85 A finales del siglo XVIII comenzaremos a ver a la comunidad extranjera en el poder, ocupando los cargos de síndico personero y diputado del común. Véase anexo. Figuras 12 y 14.

86 AMV. MOA (1790). Caja 9. Exp.14. Véase anexo. Figuras 16, 17 y 18. 
En el caso de Vinaròs un ejemplo demostrativo sería el de Juan Bautista Lasala (Lassala) ${ }^{87}$. Negociante desde los quince años que llegó a poseer nueve bienes raíces en Vinaròs, según el Padrón de riqueza de $1790^{88}$. No obstante, su padre llegó a reunir más de dieciocho propiedades en el término de Vinaròs y alrededores, de entre los cuales contaba con nueve inmuebles y tres almacenes para desempeñar sus actividades comerciales. Así pues, como señala Brilli89 la adquisición de inmuebles y bienes raíces aseguraba de manera rentable la preservación de una posición económica acomodada. Pues, en situaciones de penuria y necesidad podían llegar a alquilarse o venderse para continuar invirtiendo capital. Sea como fuere, ello probaría que la tenencia de numerosos inmuebles podría servir, no únicamente como residencia necesaria sino también como forma de inversión. Aunque este grupo social no supusiera un tanto por ciento elevado de la población, su aportación tributaria a las cargas del Estado, sí era significativa. Pues, eran esos vecinos comerciantes y tratantes (junto con los hacendados y escribanos) de Vinaròs los que contribuían con una cuota media y máxima (no hay casos de que paguen la mínima) al equivalente, dada la eficiente actividad comercial de esta localidad 90 .

Por otro lado, retomando las diferentes capacidades de negocio que podían albergarse en el sector comercial, se encontrarían los pequeños comerciantes, esto es, propietarios de tiendas o botigueros, que dentro de la élite comercial destacada en el grupo de pudientes de la villa de Vinaròs en 179891, significaba el grueso de este sector. Estos tenderos, a diferencia de los grandes comerciantes que se dedicaban a exportar e importar los productos, se ocupaban de vender tales bienes en sus locales o almacenes ${ }^{92}$. Sin embargo, podía darse la situación de que el propio tendero fuera el mismo abastecedor de mercancías para su establecimiento. Este caso se daba, principalmente, entre aquellos que eran extranjeros. En Vinaròs encontramos numerosos comerciantes de diferente nacionalidad ${ }^{93}$, entre ellos

87 AMV. "Relación del vecindario general de la villa de Vinaròs en el año 1754". Caja X. Exp.3.

88 AMV. Grandes formatos. Padrón de riqueza (1790).

89 BRILLI, C. (2013): "La importancia de hacerse español: la élite mercantil genovesa de Cádiz en el siglo XVIII". EEHA, p. 240.

90 ROMEU LLORACH, J. (1981): El sistema fiscal valenciano (1715-1823). Vinaròs, pp. 34-35.

91 AMV. MOA (1798). Lista de pudientes. Caja 9. Exp.14.

92 RAMIRO MOYA, F. (2012): Mujeres y trabajo en la Zaragoza del siglo XVIII. Zaragoza, p. 220.

93 Aunque nos hemos centrado en la élite comercial, también hemos querido reflejar la distribución por oficios de los extranjeros que habitaron en Vinaròs a finales de siglo. Véase anexo. Figuras 16, 17 y 18 
podemos distinguir a don Francisco $\mathrm{O}^{\prime} \mathrm{Sullivan}^{94}$, de origen irlandés, quien poseía una casa en el arrabal del Ángel con su fábrica de aguardiente y almacén ${ }^{95}$.

Por lo que respecta a las diferencias dentro del grupo extranjero, Fernández Pérez ${ }^{96}$ establece que era la colonia francesa la que contaba con mercaderes de gran capacidad negociadora vinculados con casas de comercio de importante capital común. Ciertamente, en Vinaròs tiene lugar esta situación, siendo el grupo galo la comunidad extranjera con más inclinación a desarrollar los oficios de los grandes comerciantes, como son los de negociante y tratante. De hecho, algunos llegarán a ocupar importantes cargos, como el negociante Jaime Camón (vicecónsul de Francia) y/o el negociante Juan Loustau (privilegiado por la Real Junta de Comercio) ${ }^{97}$.

\subsection{Formas de integración en la élite social}

Con el fin de afianzar y aumentar el poder y los beneficios, esta parte más distinguida de la élite comercial extranjera establecía la estrategia matrimonial de asociarse a relevantes familias de comerciantes. Un claro ejemplo lo hallamos en los matrimonios establecidos por las hermanas Teresa y $M^{a}$ Rosa Camón -hijas de Jaime Camón, vicecónsul de Francia- ambas casadas con negociantes franceses: Joseph Laberon Duclos, y Juan Guilheume Laborde, respectivamente ${ }^{98}$. Curiosamente, ambos yernos lograrán ser vicecónsules en el futuro: Laberon en 1781 y Guilheume en 1798. Por tanto, se matrimoniaban para relacionarse profesionalmente y aumentar su patrimonio e influencia en el mundo comercial ${ }^{99}$.

No obstante, analizando a los sujetos de este grupo comercial, notamos que el predominio de matrimonios entre varones extranjeros con mujeres

94 Dentro de esta clase pudiente podemos encontrar la figura de don Joan Killi Kelli, mercader de origen irlandés que comerciaba también en el extranjero. AMV. Grandes formatos. Padrón general de riqueza. (1811). Riqueza comercial.

95 AMV. Grandes formatos. Padrón de riqueza (1790).

96 FERNÁNDEZ PÉREZ, P. (1995): "Alianzas familiares y reproducción social de la élite mercantil de Cádiz, 1700-1812". Trocadero: revista de historia moderna y contemporánea. Universidad de Barcelona, pp. 57-58.

97 AMV. "Relación del vecindario general de la villa de Vinaròs en el año 1754". Caja X. Exp.3. Véase anexo. Figuras 15 y 19

98 Véase anexo. Figuras 15 y 17.

99 Véase anexo. Figuras 15 y 17. 
vinarocenses es mayor que el de extranjeros con extranjeras. Pues, nos hallamos con un $60 \%$ de este grupo de inmigrantes que habían contraído matrimonio con mujeres nacidas en Vinaròs, frente a un $40 \%$ de los extranjeros que se habían casado con mujeres procedentes de otros reinos europeos ${ }^{100}$. Vemos, entonces, que no solo utilizaban políitica endogámica para casarse sino también exogámica.

Asociarse con familias oriundas de un núcleo urbano determinado era una táctica eficaz para integrarse dentro de la sociedad y la redes comerciales de ésta. Pero, también casarse con comerciantes extranjeros bien posicionados podía implicar adentrarse y asegurar un acceso a la esfera de las élites mercantiles, no solo a nivel local sino también en el ámbito de ampliar sus posibilidades comerciales. En Vinaròs vemos que esto sucede entre las familias de negociantes Camón-Pons Roger, matrimoniándose $M^{a}$ Engracia Pons Roger con Jaime Camón Lacaseta ${ }^{101}$. Este último era -como hemos comentado más arriba- negociante francés y vicecónsul de Francia; ella procedía de una familia de mercaderes arraigados, también, en el poder político municipal de Vinaròs ${ }^{102}$.

De modo que era manifiesta la tendencia de las familias comerciantes a emparentarse con otras del mismo sector para así preservar e incluso prosperar dentro y fuera de la élite comercial. Prueba de ello es el matrimonio entre Pedro Miramón, negociante francés, casado con Casilda Loustau, hija del negociante francés, privilegiado por la Real Junta de Comercio, Juan Loustau ${ }^{103}$.

Por tanto, al parecer en la sociedad vinarocense del siglo XVIII era coherente que mercaderes extranjeros llegaran a aliarse con familias originarias de $\mathrm{Vi}$ naròs. Francisco Bonafont Busquet, negociante procedente de la población aquitana de Bruges (Francia), contrajo primeras nupcias en 1772 con $\mathrm{M}^{\circ}$ Agustina Mayó Oliu, natural de Vinaròs, hija de marineros vinarocenses ${ }^{104}$. También, Simón Crosad (Crozad) Vilar, tendero francés, procedente de la población de Orón, en la región de Lorena, contrajo nupcias en 1749 con la vinarocense, Magdalena Trifu Mallach, hija del Dr. Nicolás Trifu y Agustina Mallach ${ }^{105}$.

100 Véase anexo. Figura 15.

101 APV. Libro de matrimonios, volumen IV.1746-1775. Libro de matrimonios, volumen III. 17151745. Véase anexo. Figura 20.

102 Véase anexo. Figura 2, 4, 5, 15 y 20

103 Véase anexo. Figura 15.

104 APV. Libro de matrimonios, volumen IV. 1746-1775. Véase anexo. Figura 15.

105 APV. Libro de matrimonios, volumen IV. 1746-1775. Véase anexo. Figura 15. 
Así pues, los enlaces entre negociantes extranjeros no solo se producían una vez asentados en la villa, sino también antes de llegar e instalarse en ella. Encontramos un caso en el que el matrimonio se había concertado previamente en el país de origen y no en la sociedad de acogida. Eduardo Estrich Serton, negociante procedente de Ennis, abandona su Irlanda natal acompañado de su esposa, Sara Fitz-Gerald Madir para establecerse e iniciar una nueva vida en la villa de Vinaròs. Estrich aparecía ya reflejado en el padrón de 1754, figurando como soltero ${ }^{106}$. No obstante, en 1767 volvería a Dublín para contraer nupcias con su prometida. En la llegada de ambos a Vinaròs, volverán a desposarse en $1768^{107}$.

Otra de las formas de incorporación por parte de los comerciantes en la élite social vinarocense, fue el afán de integración como miembros del poder municipal de la villa. Aunque su presencia haya sido nula en los primeros ayuntamientos del siglo $\mathrm{XV}_{\mathrm{III}}{ }^{108}$, tenemos constancia de la asistencia de este sector en los diferentes cargos concejiles a partir de la primera mitad del siglo.

Negociante y síndico procurador general (1754) $)^{109}$ era Joseph Juan y Mercé, casado con Magdalena Piñol, con quien tuvo cuatro hijas ( $M^{a}$ Magdalena, Josepha $M^{a}$, Carmela, $M^{a}$ Teresa y $M^{a}$ Brígida). Supo consolidarse y mantener su presencia en el cabildo, llegando a ocupar el cargo de alcalde ordinario en 1766, así como, el de regidor decano en 1776. Además, pudo verse su estatus reforzado tanto en el ámbito político como en el socioeconómico debido a su matrimonio con una integrante de la saga de los Piñol, respetada familia de plateros vinarocenses con influencia en las estructuras del gobierno municipal de la villa ${ }^{110}$.

Mientras los comerciantes vinarocenses llevaban accediendo a los diferentes oficios y cargos del gobierno local desde mediados del Setecientos, la élite comercial extranjera tardará en aparecer en la esfera política municipal, y no lo hará hasta finales de tal siglo, momento en el que estén completamente asentados en la villa, y sean aceptados por el resto de la élite. Conforme apunta Brilli, la escasa intervención en el poder político puede que se debiera, no por la indiferencia que pudieran sentir estos comercian-

106 AMV. "Relación del vecindario general de la villa de Vinaròs en el año 1754". Caja X. Exp.3.

107 APV. Libro de matrimonios, volumen IV. 1746-1775. Véase anexo. Figura 15.

108 Véase anexo. Figura 1.

109 AMV. "Relación del vecindario general de la villa de Vinaròs en el año 1754". Caja X. Exp.3.

110 Véase anexo. Figuras 4, 6, 9 y 14. 
tes hacia la política sino por las restricciones establecidas por el propio cabildo. En la ciudad portuaria de Cádiz se logró excluir a la clase comerciante extranjera de acceder a las regidurías, gracias a los diversos donativos y préstamos por parte de los miembros del corpus político, favoreciendo el acceso de familiares $y$, por tanto, dificultando el de personas externas ${ }^{111}$. En el caso de Vinaròs, observamos que los comerciantes extranjeros no ocupan las regidurías. Sin embargo, con la llegada de la Reforma Municipal de 1766, tendrán la oportunidad de acceder al ayuntamiento con los nuevos cargos de síndico personero y diputados del común. Será, pues, entonces cuando comencemos a vislumbrar la figura de los extranjeros en el poder político municipal. De entre todos los individuos que hemos podido identificar ejerciendo estos cargos, tres fueron comerciantes. En 1784 fueron elegidos los negociantes franceses Juan Guilheume ${ }^{112}$ y Francisco Bonafont para diputado y síndico personero del común, respectivamente ${ }^{113}$. Francisco Alsina, de Vinaròs, sería otro de los comerciantes que ocuparía el cargo de diputado en $1798^{114}$.

\section{Conclusiones}

Dicha investigación no tiene la intención de exponer unas conclusiones determinantes, sino presentar, de la manera más minuciosa posible, los resultados que hemos obtenido a raíz de nuestro análisis. Así, resultaría interesante que futuros trabajos relacionados con esta temática se llevaran a cabo con tal de contrastar conclusiones. No obstante, nos parecía interesante sacar a la luz toda esta información, ideando una nueva vía de estudio.

Inicialmente, vemos que la oligarquía de Vinaròs aparece representada, básicamente, en el panorama político y relacionada con el mundo del comercio. No obstante, se podía vislumbrar desde un principio una evidente distinción en la sociedad vinarocense de mediados del Setecientos con el estudio del padrón de habitantes, realizado en 1754, en donde se especificaban los oficios, la forma en que se estructuraba la urbe (a Callehita), la clasificación de los vecinos que conformaban dicho municipio según el sector social del que procedían, sus uniones matrimoniales, etc.

111 BRILLI, C. (2013), Op. Cit., p. 250.

112 Juan Guilheume logrará ser vicecónsul francés en 1798.

113 Véase anexo. Figuras 12 y 14.

114 Véase anexo. Figura 12. 
Así, una de las partes esenciales en el ascenso social vinarocense se ve reflejado en el ámbito político y administrativo, permitiendo la preservación y reproducción del poder de distintas familias. Por un lado, observamos que los puestos municipales facilitan el incremento del poder e influencia que estos individuos podían llegar a albergar. Sin embargo, por otro lado el acceso al control local se veía facilitado si el sujeto era de condición noble, como por ejemplo las familias de los Febrer y las de los Julián, quienes ocuparían los cargos más notables de la estructura política y administrativa en el término de Vinaròs. Empero, no todos los cargos políticos tenían que contar con el mismo nivel de prestigio, pero los que sí lo hacían era por la preservación de los mismos en el Ayuntamiento. Por tanto, vemos a lo largo de nuestro estudio que diferentes regidores se mantienen en el poder ejerciendo cargos políticos, e incluso conseguirán ascender.

El ejercicio de poder municipal supondrá el eje de tácticas y maniobras que permitan llevar acabo la consolidación de la autoridad y supremacía social. Así pues, una de las formas de mantenerse y acrecentar el poder, tanto político como socioeconómico era a través de las diversas estrategias matrimoniales. Encontramos familias de regidores que se relacionaban entre sí, por ejemplo, los Escrivano y los Morales.

Asimismo, hemos podido observar ciertas estrategias de la élite comercial, en este caso la élite extranjera -en donde destacan los vicecónsules- estableciendo lazos con las familias oriundas de Vinaròs para poder asentarse y ser aceptados por la élite comercial con el fin de acceder, de esa manera, a los espacios de poder. Un caso interesante al respecto sería el del negociante francés Francisco Bonafont, cuyo matrimonio con María Agustina Mayó Oliu, oriunda de Vinaròs, pudo darle acceso a desempeñar cargos de gobierno, en este caso, en calidad de síndico personero del común. Con ello demostramos que al casarse no solo incrementan perspectivas en el ámbito comercial, sino que en el caso de los extranjeros, pueden tener un papel representativo en las diferentes esferas de control político.

Con todo ello, tras haber examinado todas las peculiaridades de este grupo social, vemos que colectivos relativamente poderosos acabaron por emparentarse con la tentativa de unir sus influencias, para así incrementar el prestigio de sus componentes. De hecho, podríamos hablar de una endogamia dentro de la clase política, dado que al aliarse familias de regidores, se conformaban matrimonios de idéntico sector social. En el caso de los extranjeros podrían darse también los enlaces endogámicos pero en $\mathrm{Vi}$ naròs primaban los exogámicos, con el fin de establecerse en la sociedad de acogida o alcanzar nuevos horizontes comerciales como ocurría con la élite mercantil. 
Podemos concluir, por tanto, que el dominio municipal y comercial, así como, las maniobras familiares resultan ser elementos claves para la consolidación y desarrollo del poder por parte de esta oligarquía en el municipio de Vinaròs a partir de la segunda mitad del siglo XVIII.

\section{Biblografía}

AMOrós VIDAL, F. (2002): "El Síndico personero: la voz del común". En III Congreso Turístico Cultural del Valle de Ricote, pp. 405-425.

Aranda Pérez, F. J. (1991): "Prosopografía y particiones de bienes: una propuesta metodológica para el estudio de las oligarquías urbanas castellanas en la Edad Media". Cuadernos de Historia Moderna. N.12, pp. 259-276.

AsENJO GoNZÁlEZ, M. (1981): "Labradores ricos: nacimiento de una oligarquía rural en la Segovia del siglo xv". La España Medieval, 4, pp. 63-85.

Bernabé GIL, D. (2001): "Insaculación, oligarquía e intervencionismo regio en la villa de Xixona (ss. XVI-XVII)". Revista de historia moderna. Anales de la universidad de Alicante. N. 19, pp. 79-122.

BRILI, C. (2013): "La importancia de hacerse español: la élite mercantil genovesa de Cádiz en el siglo XVIII". EEHA, pp. 227-255.

Cózar GutiérRez, R. (2009): «"De lo que yo el infrascrito escribano doy fe". Los escribanos de la villa de Albacete durante el siglo XVIII». Revista de historia moderna, 28, pp. 269-299.

Cuesta Martínez, M. (1997): Oficios públicos y sociedad. Administración urbana y relaciones de poder en la Córdoba de finales del Antiguo Régimen. Universidad de Córdoba, Córdoba, p.358.

Extremera Extremera, M. A. (2001): "Los escribanos de Castilla en la Edad Moderna. Nuevas Líneas de Investigación". Chronica Nova, 28, pp. 160 161.

Fernández NadAL, C.M. (2003): El Corregimiento de Castellón en época de Carlos III: entre la continuidad y la reforma. Ayuntamiento de Castellón, Castellón.

FerNÁNDez Pérez, P. (1995): "Alianzas familiares y reproducción social de la élite mercantil de Cádiz, 1700-1812". Trocadero: revista de historia moderna y contemporánea. Universidad de Barcelona, pp. 57-58 
GIMÉNEZ López, E. (1990): "El municipio borbónico". Historia de la ciudad de Alicante. Tomo III: Historia Moderna. Universidad de Alicante Gimeno Sanfeliu, Ma. J. (1990): La oligarquía urbana de Castelló en el siglo XVIII. Castellón de la Plana, Ayuntamiento de Castellón. Gimeno Sanfellu, Ma J. (1998): Patrimonio, parentesco y poder. Castelló (XVI-XIX). Universitat Jaume I. Diputación de Castellón. Castellón.

Gómez NaVArRo, S. (2001): La letra y el espíritu de la letra: notario, formulario notarial e historia. Universidad de Córdoba.

Gómez ZorRaQuino, J.I. (2003): "Ni señores, ni campesinos-artesanos. El gobierno de los ciudadanos en Aragón". Burgueses o ciudadanos en la España moderna. N.6, pp. 384-385.

IRLES VICENTE, M.C. (1991): Los regidores valencianos. Perfil sociológico de una élite de poder. Universidad de Alicante, pp. 192-193.

Molas Ribalta, P. (2004): "Diputats i síndics a l'ajuntament borbònic de Barcelona (1760-1808)". Revista de Dret Històric Català. Societat Catalana d'Estudis Jurídics. N. 4, pp.11-27.

Ramiro Moya, F. (2012): Mujeres y trabajo en la Zaragoza del siglo XVIII. Zaragoza.

ROMEU LIORACH, J. (1981): El sistema fiscal valenciano (1715-1823). Vinaròs. 


\section{Anexo}

FIGURA 1. Ayuntamiento de 1710

\begin{tabular}{|l|l|}
\hline Cargos & \multicolumn{1}{|c|}{ Año 1710 } \\
\hline Alcalde y juez ordinario & Juan Bautista Febrer y la Torre (noble) \\
\hline Regidor primero & Dr. Agustin Salvador \\
\hline Regidor segundo & Dr. Faustino Cruz \\
\hline Regidor tercero & Bautista Esteller (ciudadano) \\
\hline Regidor cuarto & Gregorio Gallén \\
\hline Sindico procurador general & Joseph Vidal \\
\hline Alcaldes de la Hermandad & Sebastián Miralles y Miguel Esteller \\
\hline Escribano & Mathias Domingo Mallach \\
\hline
\end{tabular}

Fuente: Elaboración propia en base a la documentación consultada. AMV. Llibres del consell. Manos de Consejo y deliberaciones. (1710-1713)

FIgURA 2. Ayuntamiento de 1755

\begin{tabular}{|l|l|}
\hline Cargos & \\
\hline Alcalde ordinario & Antonio Covarsi \\
\hline Regidor primero & Agustin Corrau \\
\hline Regidor segundo & Bautista Miralles y Quixal \\
\hline Regidor tercero & Bautista Gombau de Bartholomé \\
\hline Regidor cuarto & Thomás Fomer \\
\hline Sindico procurador general & Francisco Escrivano \\
\hline \multirow{2}{*}{ Juez contador } & Joseph Borrell \\
\cline { 2 - 2 } & Damián Pons y Roger \\
\hline Alguacil mayor & Joseph Doménech y Palau \\
\hline \multirow{2}{*}{ Valedores (expertos labradores) } & Sebastián Domenech \\
\cline { 2 - 2 } & Bautista Miralles de Roldán \\
\cline { 2 - 2 } & Agustin Esteller \\
\cline { 2 - 2 } & Damián Domenech \\
\hline
\end{tabular}

Fuente: AMV. Mano de órdenes y acuerdos. (1755). Caja 6. Exp.19.

Figura 3. Ayuntamiento de 1784

\begin{tabular}{|l|l|}
\hline Cargos & \multicolumn{1}{|c|}{ Año 1784 } \\
\hline Alcalde y juez ordinario & A sustín Esteller y Pedro \\
\hline Regidor primero/mayor/decano & Sebastián Reverter \\
\hline Regidor segundo & Josef Escura \\
\hline Regidor tercero & Josef Lacruz \\
\hline Regidor cuarto & Bartholomé Querol \\
\hline Sindico procurador general & Josef Piñol \\
\hline Lugarteniente de Alcalde & Agustin Giner \\
\hline Alcalde de monte 1 & Sebastián Chaler \\
\hline Alcalde de monte 2 & \\
\hline Ministro pregonero público & Carlos Chulvi \\
\hline Predicador de la Cuaresma & Juan Bautista Briz \\
\hline Maestros albañiles & Pedro Fontes, Vicente Tosca, Miguel Peris \\
\hline Maestros carpinteros & Nicolás Santus, Pascual Vives \\
\hline Maestros cerrajeros & Joseph Verdera, Antonio Agell \\
\hline Morbero & Manuel Martinez \\
\hline Receptor de la Bula & Andrés Lovella \\
\hline Diputados de la Junta de Propios & Dr. D. Sebastiän Forner \\
\hline Administrador del arriendo de la Nieve & Miguel Sabater \\
\hline Administrador del arriendo de abasto y carnes & Christóbal Roig \\
\hline & Juan Guilheume \\
\hline Diputados del Común & Joaquin Ángel de Izco \\
\hline Síndico Personero & Francisco Bonafont \\
\hline Dulzainero & Christóbal Soriano \\
\hline Sacristanes de la Virgen & Joaquín Sisarch Francisco Costa \\
\hline
\end{tabular}

Fuente: AMV. Mano de órdenes y acuerdos. Caja 8. Exp.8. 
FIgURA 4. Cuadro de Alcaldes Ordinarios

\begin{tabular}{|l|l|l|}
\hline \multicolumn{1}{|l|}{ ño } & Alcalde ordinario & Oficio \\
\hline 1755 & Antoni Covarsi & Ciudadano \\
\hline 1760 & Damián Pons y Roger & Negociante \\
\hline 1763 & Agustín Corrau & Cerero \\
\hline 1764 & Carlos Piñol Mayor & \\
\hline 1766 & Joseph Juan y Mercé & Negociante \\
\hline 1767 & Agustin Corrau & Cerero \\
\hline 1768 & Joseph Forner de Joseph & Labrador \\
\hline 1769 & Francisco Escrivano & \\
\hline 1773 & Dr. Antonio Tarragó & Médico \\
\hline 1776 & Dr. Pedro Antonio Cruz & Abogado, ciudadano \\
\hline 1777 & Dr. Francisco Esteve & Abogado de los Reales Consejos \\
\hline 1778 & Joseph Forner de Joseph & \\
\hline 1781 & Francisco Escrivano & Abogado de los Reales Consejos \\
\hline 1782 & Francisco Fscrivano & Abogado de los Reales Consejos \\
\hline 1783 & Josef Pons y Roger & Familiar del Santo Oficio \\
\hline 1784 & Agustin Esteller y Pedro & \\
\hline 1786 & D. Juan Bautista Febrer y Ferrán & Caballero \\
\hline 1790 & Dr. Antonio Tarragó & Médico \\
\hline 1791 & D. Francisco Luis Julián & Caballero \\
\hline 1792 & Agustín Esteller de Pedro & Labrador \\
\hline 1793 & Nicolás Doménech & Fscribano \\
\hline 1794 & Dr. D. Jayme Miralles & Abogado \\
\hline 1796 & Ildefonso Miralles & Labrador \\
\hline 1797 & Josef Jordà & Hacendado \\
\hline 1798 & Manuel Escrivano & \\
\hline
\end{tabular}

Fuente: Elaboración propia en base a la documentación consultada AMV, MOA, caja 6, expediente: 19 (1755). Caja 7, expedientes: 4 (1760), 6 (1763), 7 (1764), 10 (1767), 11 (1768), 13 (1769). MOA, caja 8, expedientes 1(1773), 3 (1776), 4 (1777), 5 (1778). MOA, caja 9, expedientes: 1 (1783), 8 (1790). 10, (1792). 9 (1791), 10 (1792), 11 (1793), 12 (1794), 13 (1796), 19 (1797).

Figura 5. Cuadro de Regidores Decanos

\begin{tabular}{|l|l|l|}
\hline Año & Regidores & Oficio \\
\hline 1755 & Agustin Corrau & Cerero \\
\hline 1760 & Agustin Piera & \\
\hline 1763 & Dr. Pedro Antonio Cruz & Abogado, ciudadano \\
\hline 1764 & Dr. Antonio Tarragó & Médico \\
\hline 1766 & Francisco Escrivano & \\
\hline 1767 & Francisco Reguart & Escribano \\
\hline 1768 & Domingo Fomer & Labrador \\
\hline 1769 & Joseph Miralles y Roldán & Labrador \\
\hline 1773 & Francisco Reguart & Escribano \\
\hline 1776 & Joseph Juan y Mercé & Negociante \\
\hline 1777 & Damián Pons y Roger & Negociante \\
\hline 1778 & Bautista Garcia & Labrador \\
\hline 1781 & Dr. Pedro Antonio Cruz & Abogado y ciudadano \\
\hline 1782 & Dr. Pedro Antonio Cruz & Abogado y ciudadano \\
\hline 1783 & Francisco Reguart & Escribano \\
\hline 1784 & Sebastián Reverter & \\
\hline 1786 & Agustin Sabater & Escribano \\
\hline 1790 & Josef Pons & Familiar del Santo Oficio \\
\hline 1791 & Maximiano Morales & Teniente \\
\hline 1792 & D. Scbastián Forner & Abogado de los Reales Consejos \\
\hline 1793 & Dr. Pedro Antonio Cruz & Abogado \\
\hline 1794 & Josef Forner & Labrador \\
\hline 1796 & Bautista Dufor & Cerero \\
\hline 1797 & Nicolàs Domenech & \\
\hline 1798 & Agustin Corrau & Labrador \\
\hline & & \\
\hline
\end{tabular}

Fuente: Elaboración propia en base a la documentación consultada $A M V, M O A$, caja 6, expediente: 19 (1755). MOA, caja 7, expedientes: 4 (1760), 6 (1763), 7 (1764), 10 (1767), 11 (1768), 13 (1769). MOA, caja 8, expedientes: 1 (1773), 3 (1776), 4 (1777), 5 (1778), 8 (1784). MOA, caja 9, expedientes: 5 (1786), 8 (1790), 9 (1791), 10 (1792), 11 (1793), 12 (1794), 13 (1796), 14 (1797). 
Figura 6. Cuadro de Regidores Segundos

\begin{tabular}{|l|l|l|}
\hline Año & Regidor segundo & Ofício \\
\hline 1755 & Bautista Miralles y Quixal & \\
\hline 1760 & Joseph Miralles & Labrador \\
\hline 1763 & Joseph Miralles y Forner & \\
\hline 1764 & Damián Doménech & Teniente \\
\hline 1766 & Maximiano Morales & Platero \\
\hline 1767 & Bautista Piñol & \\
\hline 1768 & Joseph Miralles y Coves & Labrador \\
\hline 1769 & Vicente Doménech & \\
\hline 1773 & Joseph Miralles y Coves & Labrador \\
\hline 1776 & Sevastián Chaler de Sevastián & Labrador \\
\hline 1777 & Francisco Bordes & \\
\hline 1778 & Miguel Miralles de Miguel & \\
\hline 1781 & Juan Forner & \\
\hline 1782 & Juan Fomer & Labrador \\
\hline 1783 & Ildefonso Miralles & Labrador \\
\hline 1784 & Josef Escura & Labrador \\
\hline 1786 & Francisco Bordes & Matriculado \\
\hline 1790 & Pedro Meseguer & Matriculado \\
\hline 1791 & Joseph Miralles & Matriculado \\
\hline 1792 & Agustin Bordes & Matriculado \\
\hline 1793 & Joseph Oliu & Matriculado \\
\hline 1794 & Agustin Pasqual & Matriculado \\
\hline 1796 & Christóbal Clapes & Matriculado \\
\hline 1797 & Thomás Agustin Obiol & Matriculado \\
\hline 1798 & Agustin Ribera & \\
\hline
\end{tabular}

Fuente: Elaboración propia en base a la documentación consultada $A M V, M O A$, caja 6, expediente: 19 (1755). MOA, caja 7, expedientes: 4 (1760), 6 (1763), 7 (1764), 10 (1767), 11 (1768), 13 (1769). MOA, caja 8, expedientes: 1 (1773), 3 (1776), 4 (1777), 5 (1778), 8 (1784). MOA, caja 9, expedientes: 5 (1786), 8 (1790), 9 (1791), 10 (1792), 11 (1793), 12 (1794), 13 (1796), 14 (1797).

Figura 7. Cuadro de Regidores Terceros

\begin{tabular}{|l|l|l|}
\hline Año & Regidor tercero & Oficio \\
\hline 1755 & Bautista Gombau de Bartholomé & \\
\hline 1763 & Joseph Forner y Segarra & Soldado de la costa \\
\hline 1764 & Bautista García & \\
\hline 1766 & Miguel Miralles y Chaler & \\
\hline 1767 & Ildefonso Miralles & Labrador \\
\hline 1768 & Miguel Domenech y Chichal & \\
\hline 1769 & Manuel Miralles & Labrador \\
\hline 1773 & Joseph Doménech Palau & Labrador \\
\hline 1776 & Sebastián Miralles de Joseph & \\
\hline 1777 & Francisco Miralles y Serret & Labrador \\
\hline 1778 & Josef Escura & Labrador \\
\hline 1783 & Sebastián Miralles de Joseph & \\
\hline 1784 & Josef Lacruz & Pasamanero y cabo \\
\hline 1786 & Silvestre Gassó & Labrador \\
\hline 1790 & Juan Bautista Frayle & Matriculado \\
\hline 1791 & Agustín Ribera & Matriculado \\
\hline 1792 & Thomás Agustin Obiol & Matriculado \\
\hline 1793 & Joseph Gombau & Matriculado \\
\hline 1794 & Josef Mayó & Matriculado \\
\hline 1796 & Manuel Calsada & Matriculado \\
\hline 1797 & Agustin Bordes & Matriculado \\
\hline 1798 & Pedro Vicente Guarch & Matriculado \\
\hline
\end{tabular}

Fuente: Elaboración propia en base a la documentación consultada $A M V, M O A$, caja 6, expediente: 19 (1755). MOA, caja 7, expedientes: 4 (1760), 6 (1763), 7 (1764), 10 (1767), 11 (1768), 13 (1769). MOA, caja 8, expedientes: 1 (1773), 3 (1776), 4 (1777), 5 (1778), 8 (1784). MOA, caja 9, expedientes: 5 (1786), 8 (1790), 9 (1791), 10 (1792), 11 (1793), 12 (1794), 13 (1796), 14 (1797). 
Figura 8. Cuadro de Regidores Cuartos

\begin{tabular}{|c|l|l|}
\hline Año & Regidor cuarto & Oficio \\
\hline 1755 & Thomás Forner & \\
\hline 1763 & Sebastián Roso & Tratante \\
\hline 1764 & Joseph Doménech y Palau & \\
\hline 1766 & Sebastián Redó & \\
\hline 1767 & Sebastián Chaler de Sebastián & Labrador \\
\hline 1768 & Cristobal Agramunt & Labrador \\
\hline 1769 & Bautista Fomer de Gaspar & \\
\hline 1773 & Joseph Planesa & \\
\hline 1776 & Benito Cervera de Thomás & Labrador \\
\hline 1777 & Pasqual Doménech & Labrador \\
\hline 1778 & Bartholomé Querol & Labrador \\
\hline 1783 & Juan Bautista Arnau de Bautista & \\
\hline 1784 & Bartholomé Querol & Labrador \\
\hline 1786 & Sebastián Farga & Labrador \\
\hline 1790 & Agustin Esteller de Agustin & Labrador \\
\hline 1791 & Juan Bautista Gascó & Labrador \\
\hline 1792 & Joscph Forner de Thomás & Labrador \\
\hline 1793 & Tomás Agustín Chaler & Labrador \\
\hline 1794 & Josef Gombau & Labrador \\
\hline 1796 & Francisco Polo de Lorenzo & Labrador \\
\hline 1797 & Domingo Doménech de Christóbal & Familiar del Santo Oficio y labrador \\
\hline
\end{tabular}

Fuente: Elaboración propia en base a la documentación consultada $A M V, M O A$, caja 6, expediente: 19 (1755). MOA, caja 7, expedientes: 4 (1760), 6 (1763), 7 (1764), 10 (1767), 11 (1768), 13 (1769). MOA, caja 8, expedientes: 1 (1773), 3 (1776), 4 (1777), 5 (1778), 8 (1784). MOA, caja 9, expedientes: 5 (1786), 8 (1790), 9 (1791), 10 (1792), 11 (1793), 12 (1794), 13 (1796), 14 (1797).

Figura 9. Cuadro de Síndicos Procuradores Generales

\begin{tabular}{|l|l|l|}
\hline Año & \multicolumn{1}{|c|}{ Síndico procurador general } & Oficio \\
\hline 1755 & Francisco Escrivano & \\
\hline 1760 & Bautista Piñol & Platero \\
\hline 1763 & Francisco Reguart & Escribano \\
\hline 1764 & Joscph Servera Doménech & \\
\hline 1766 & Carlos Bellafont & \\
\hline 1767 & Joseph Doménech y Palau & \\
\hline 1768 & Juan Bautista Forner y Solé & Hacendado \\
\hline 1769 & Joseph Jordà de Joseph & Platero \\
\hline 1773 & Bautista Piñol & \\
\hline 1774 & Agustin Juan & Labrador \\
\hline 1776 & Domingo Forner de Vicente & Platero \\
\hline 1777 & Bautista Piñol & Labrador \\
\hline 1778 & Domingo Arnau de Agustin & \\
\hline 1781 & Juan Bautista Fornés & \\
\hline 1782 & Juan Bautista Fornés & \\
\hline 1783 & Agustin Juan de Bartholomé & \\
\hline 1784 & Josef Piñol & Cerero \\
\hline 1786 & Thomás Piera & Pasamanero y cabo \\
\hline 1790 & Josef Lacruz & Matriculado \\
\hline 1791 & Pedro Vicente Guarch & Matriculado \\
\hline 1792 & Agustin Darder Mayor & Matriculado \\
\hline 1793 & Bautista Abella & Matriculado \\
\hline 1794 & Agustin Gombau de Josef & Matriculado \\
\hline 1796 & Pasqual Miralles Menor & \\
\hline 1797 & Manuel Costa & \\
\hline 1798 & Antonio Pla & \\
\hline & & \\
\hline
\end{tabular}

Fuente: Elaboración propia en base a la documentación consultada $A M V, M O A$, caja 6, expediente: 19 (1755). MOA, caja 7, expedientes: 4 (1760), 6 (1763), 7 (1764), 10 (1767), 11 (1768), 13 (1769). MOA, caja 8, expedientes: 1 (1773), 3 (1776), 4 (1777), 5 (1778), 8 (1784). MOA, caja 9, expedientes: 5 (1786), 8 (1790), 9 (1791), 10 (1792), 11 (1793), 12 (1794), 13 (1796), 14 (1797). 
Figura 10. Cuadro de Lugartenientes de Alcalde

\begin{tabular}{|l|l|l|}
\hline Año & Lugarteniente de Alcalde & Oficio \\
\hline 1763 & Ildefonso Miralles & Labrador \\
\hline 1764 & Sebastián Chaler & \\
\hline 1766 & Bautista Forner de Gaspar & \\
\hline 1767 & Juan Forner de Francisco & \\
\hline 1768 & Sebastián Farga & Labrador \\
\hline 1769 & Francisco Miralles y Serret & Labrador \\
\hline 1773 & Juan Bautista Arnau de Joseph & \\
\hline 1776 & Bautista Leonart de Joseph & Labrador \\
\hline 1777 & Manuel Miralles de Manuel & \\
\hline 1778 & Mathías Agramunt & \\
\hline 1783 & Agustin Esteller de Agustin & \\
\hline 1784 & Agustín Giner & \\
\hline 1786 & Miguel Forner de Gila & \\
\hline 1790 & Carlos Esparduser & Matriculado \\
\hline 1791 & Pedro Doménech de Joseph & Labrador \\
\hline 1792 & Francisco Rabasa & Labrador \\
\hline 1793 & Felipe Enrich & Labrador \\
\hline 1794 & Francisco Agramunt & Labrador \\
\hline 1796 & Baptiste García & Labrador \\
\hline 1797 & Agustín Gombau & Matriculado \\
\hline 1798 & Antonio Pla & Labrador \\
\hline
\end{tabular}

Fuente: Elaboración propia en base a la documentación consultada AMV, MOA, caja 7, expedientes: 6 (1763), 7 (1764), 10 (1767), 11 (1768), 13 (1769). MOA, caja 8, expedientes: 1 (1773), 3 (1776), 4 (1777), 5 (1778), 8 (1784). MOA, caja 9, expedientes: 5 (1786), 8 (1790), 9 (1791), 10 (1792), 11 (1793), 12 (1794), 13 (1796), 14 (1797). 
Figura 11. Cuadros de Alcaldes de Monte

\begin{tabular}{|l|l|l|}
\hline Año & Alcalde de monte 1 & Oficio \\
\hline 1763 & Agustín Arnau & Labrador \\
\hline 1764 & Joseph Brau & \\
\hline 1767 & Joseph Doménech de Sebastián & \\
\hline 1768 & Joseph Miralles de Miguel & \\
\hline 1769 & Joseph Chaler de Joseph & \\
\hline 1773 & Joseph Brau & Labrador \\
\hline 1776 & Javme Doménech Mayor & \\
\hline 1777 & Christóval Agramunt & Labrador \\
\hline 1778 & Benito Cervera & Labrador \\
\hline 1783 & Joseph Miralles de Bautista & \\
\hline 1784 & Sebastián Chaler & Labrador \\
\hline 1786 & Agustin Esteller de Agustin & \\
\hline 1790 & Agustin Quixal & Labrador \\
\hline 1791 & Christóbal Sabater & Labrador \\
\hline 1792 & Miguel Forner & Labrador \\
\hline 1793 & Joseph Riba & Labrador \\
\hline 1794 & Agustin Quixal & Labrador \\
\hline 1796 & Francisco Doménech de Jaime & Labrador \\
\hline 1797 & Joseph Gombau & Matriculado \\
\hline
\end{tabular}

\begin{tabular}{|l|l|l|}
\hline Año & Alcalde de monte 2 $^{\circ}$ & Oficio \\
\hline 1773 & Miguel Forner & Labrador \\
\hline 1776 & Joseph Doménech de Sebastián & \\
\hline 1777 & Francisco Polo & Labrador \\
\hline 1778 & Silvestre Gassó & Labrador \\
\hline 1786 & Sebastián Miralles de Joseph & \\
\hline 1790 & Francisco polo de Lorenzo & Labrador \\
\hline 1791 & Ildefonso Miralles & Labrador \\
\hline 1792 & Agustin Miralles Fortuño & Labrador \\
\hline 1793 & Domingo Doménech & Labrador \\
\hline 1794 & Josef Escura & Labrador \\
\hline 1796 & Joaquin Bordes & Labrador \\
\hline 1797 & Joaquin Farga & \\
\hline
\end{tabular}

Fuente: Elaboración propia en base a la documentación consultada $A M V$, MOA, caja 7, expedientes: 6 (1764), 10 (1767), 11 (1768), 13 (1769). MOA, caja 8, expedientes: 1 (1773), 3 (1776), 4 (1777), 5 (1778). MOA, caja 9, expedientes: 1 (1783), 5 (1786), 8 (1790), 10 (1792), 9 (1791), 11 (1793), 11 (1794), 13 (1796), 19 (1797).

Fuente: Elaboración propia en base a la documentación consultada AMV, MOA, caja 8, expedientes: 1 (1773), 3 (1776), 4 (1777), 5 (1778). MOA, caja 9, expedientes: 11 (1793), 11 (1794), 13 (1796), 19 (1797). 
Figura 12. Síndicos Personeros del Común

\begin{tabular}{|l|l|}
\hline Síndico Personero & Años que ejercieron \\
\hline Dr. Francisco Esteller & $1766-1767$ \\
\hline Francisco Bonafont & 1784 \\
\hline Jaime Miralles Gil & 1790 \\
\hline Joseph Escuder & 1793 \\
\hline Gaspar Marti & 1798 \\
\hline Juan Bautista Albella & 1798 \\
\hline
\end{tabular}

Fuente: AMV. Mano de órdenes y acuerdos. (1766-1767). Caja. 7. Exp.9. Caja 8. Exp. 7. Mano de órdenes y acuerdos. (1784). Caja 8. Exp. 8. Mano de órdenes y acuerdos. (1793). Hay diputados que no hemos podido encontrar en actas. No obstante, sabemos de su existencia por las signaturas de la documentación.

Figura 13. Alcaldes de Hermandad

\begin{tabular}{|l|l|}
\hline Alcalde de Hermandad & Año que ejercieron \\
\hline Scbastián Miralles y Miguel Fsteller & 1710 \\
\hline Joseph Gombau de Paula & 1766 \\
\hline
\end{tabular}

Fuente: Elaboración propia en base a la documentación consultada AMV, Llibres del consell. Manos de Consejo y deliberaciones, caja 561, leg.3 (1710-1713). MOA, caja 8, exp. 3 (1766).

Figura 14. Diputados del común

\begin{tabular}{|l|l|}
\hline Diputados del Común & Años que ejercieron \\
\hline Francisco Reverter & $1766-1767$ \\
\hline Vicente Esteller & $1766-1767$ \\
\hline Joseph Francisco Covarsi & 1774 \\
\hline Francisco Reguart & 1781 \\
\hline Juan Fornés & 1781 \\
\hline Bautista Dufor & 1782 \\
\hline Dr. Antonio Tarragó & 1782 \\
\hline Juan Guilheume & 1784 \\
\hline Joaquin Angel de Izco & 1784 \\
\hline Pedro Barragán & 1793 \\
\hline Diego Forner & 1793 \\
\hline Francisco Alsina & 1798 \\
\hline Carlos Piñol & 1798 \\
\hline Juan Bautista Reguart & 1798 \\
\hline
\end{tabular}

Fuente: Elaboración propia en base a la documentación consultada AMV, MOA caja 7, expediente 9 (1766-1767). MOA, caja 8, expedientes: 6 (1782), 7 (1784), 8 (1793). Hay diputados que no hemos podido encontrar en actas. No obstante, sabemos de su existencia por las signaturas en la documentación. 
FIGURA 15. Cuadro y gráfico de extranjeros domiciliados en Vinaròs en 1778

\begin{tabular}{|c|c|c|c|c|c|c|c|c|}
\hline Nombre & Oficio & Nacionalidad & Cónguze & Padres & Nacionalidad padres & Suegros & Nacionalidad suegros & $\begin{array}{l}\text { Fecha de } \\
\text { easamiento }\end{array}$ \\
\hline Joseph Laberon Duclos & Negeciante & Francts & Teresa Camon & Joseph Laberon y Maria Duclos & De Marcias (Francia) & $\begin{array}{l}\text { Jayme Camón (Viceconsul francés) y } \\
\text { Maria Engracia Poes }\end{array}$ & $\begin{array}{l}\text { Padre francés madre } \\
\text { vinarosense }\end{array}$ & 1761 \\
\hline Juan Guilhcume Laborde & Negociante & Francts & Maria Rosa Camon & $\begin{array}{l}\text { Juan Francisco Guilheume y } \\
\text { Maria de Laborde }\end{array}$ & Géronce (Francia) & $\begin{array}{l}\text { Jayme Camón (Viceconsul francts) y } \\
\text { Maria Engracia Pons }\end{array}$ & $\begin{array}{l}\text { Padre francts madre } \\
\text { vinarosense }\end{array}$ & 1766 \\
\hline Francisco Bonafont Busquet & Negociante & Francts & María A ceustina Mayó Oliu & Juan Bonafont y Maria Busquet & Bruges (Francia) & Agustin Mayó y Maria Teresa Oliu & Ambos de Vinarós & 1772 \\
\hline Joseph Miran & Botiguero & Francts & Rita Borrell & $\begin{array}{l}\text { Lorenzo Miran y Maria } \\
\text { Casanovas }\end{array}$ & Francia & Pascual Borrell y Cecilia Domtnech & Ambos de Vinarós & 1749 \\
\hline Simón Crosad Vilar & Botizuero & Francets & Magdalena Trifu Mallach & Juan Crosat y Catarina Vilar & Oron, Lorena (Francia) & $\begin{array}{l}\text { De. Nicolis Trifu (médico) y Agustina } \\
\text { Mallach }\end{array}$ & Ambos de Vinaròs & 1749 \\
\hline Pedro Miramón & Negeciante & Francts & Casilda Loustau & & & $\begin{array}{l}\text { Juan Loustau, negociante privilegiado } \\
\text { por la Real Junta de Comercio }\end{array}$ & Francia & \\
\hline Juan Pechinat & Tratante & Franets & & & & & & \\
\hline Joseph White & Nezociante & Irland's & & & & & & \\
\hline Simón Adley & Negociante & Irland's & & & & & & \\
\hline Eduardo Estrich Sertion & Negociante & Irland's & Dha. Sara Fits-Gerald Madir & $\begin{array}{l}\text { D. Guillermo Estrich y Margarita } \\
\text { Serton }\end{array}$ & De Ennis (Irlanda) & $\begin{array}{l}\text { D. Miguel Fits-Gerald y Dila. } \\
\text { Margarita Madir }\end{array}$ & Waterford (Irlanda) & 1768 \\
\hline Juan Vila & Mesonero & Francts & & & & & & \\
\hline Antonio Vidal & Calderero & Francts & & & & & & \\
\hline Juan Logcume & Labrador & Francts & & & & & & \\
\hline Pedre Sucasa & Negociante & Francts & $\begin{array}{l}\text { Maria Inés Salmero (aparece } \\
\text { el segundo apellido) }\end{array}$ & Domingo Sucasa y Anna Galiay & Franceses & Pedro.... y Vicenta Salmero & Ambos de Vinarós & 1753 \\
\hline Juan Camon & Negociante & Francts & & & & & & \\
\hline Juan Bachaulet & Botiguero & Francts & Agustina Santos & Juan Bachaulet y Ana Mirin & $\begin{array}{l}\text { De Bosderros, Aquitania } \\
\text { (Francia) }\end{array}$ & Joseph Santus y Agustina Nicolau & Ambos de Vinarós & 1783 \\
\hline Pedro Casanova & Mercader & Francts & $\begin{array}{l}\text { Teresa Fornes de Lino } \\
\text { Cabades }\end{array}$ & Juan Casanova Maria Cambel & $\begin{array}{l}\text { De Beaune, Borgofla } \\
\text { (Francia) }\end{array}$ & $\begin{array}{l}\text { Sebastiain Fornis de Lino y Josepha } \\
\text { Maria Cabadts }\end{array}$ & $\begin{array}{l}\text { Padre de Vinaròs } \\
\text { Madre francesa }\end{array}$ & 1753 \\
\hline
\end{tabular}

\section{Clasificación de extranjeros según la nacionalidad de su cónyuge en 1778}

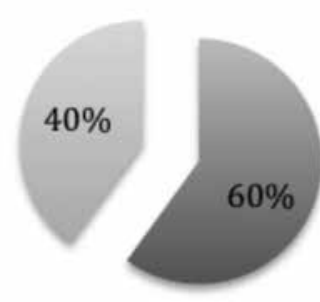

Extranjeros casados con oriundas de Vinaròs

Extranjeros casados con extranjeras

Fuente: Elaboración propia en base a la documentación consultada AMV, MOA, caja 8, exp.5 (1778). APV. Libro de matrimonios, volumen IV. 1746-1775. Libros de matrimonios, volumen $\mathrm{V}$ (1776-179). 
Figura 16. Cuadro según la nacionalidad y el oficio de los extranjeros activos domiciliados en Vinaròs en 1780

\begin{tabular}{|l|l|l|}
\hline Nombre & Oficio & Nacionalidad \\
\hline Joseph Laberon & Negociante & Francés \\
\hline Juan Guilheume & Negociante & Francés \\
\hline Juan Camon & Negociante & Francés \\
\hline Juan Bachaulet & Botiguero & Francés \\
\hline Francisco Bonafont & Negociante & Francés \\
\hline Joseph Miran & Botiguero & Francés \\
\hline Juan Pechinat & Tratante & Francés \\
\hline Carlos Matheu & Tratante & Francés \\
\hline Simón Crosad & Botiguero & Francés \\
\hline Pedro Miramon & Negociante & Francés \\
\hline Andres Robellato & Botiguero & Genovés \\
\hline Domingo Robellato & Botiguero & Genovés \\
\hline Felipe Cormi & Botiguero & Maltés \\
\hline Joaquin Cormi & Ministro de rentas & Maltés \\
\hline Joseph Escario & Zapatero & Francés \\
\hline Juan Legeume & Labrador & Francés \\
\hline Vicente Compte & Zapatero & Napolitano \\
\hline Francisco Dian & Marinero & Francés \\
\hline Antonio Vidal & Calderero & Francés \\
\hline Antonio Laboria & Calderero & Francés \\
\hline Pablo Gerada & Botiguero & Maltés \\
\hline Juan Bonig & Botiguero & Maltés \\
\hline Joseph White & Negociante & Irlandés \\
\hline
\end{tabular}

Fuente: Elaboración propia en base a la documentación consultada AMV, MOA, caja 8, exp.5 (1778). APV. Libro de matrimonios, volumen IV. 1746-1775. Libros de matrimonios, volumen $\mathrm{V}$ (1776-179). AMV, MOA, caja 8, exp.6 (1780).

Figura 17. Cuadro según la nacionalidad y el oficio de los extranjeros activos domiciliados en Vinaròs en 1781

\begin{tabular}{|l|l|l|}
\hline Nombre & Oficio & Nacionalidad \\
\hline Joseph Laberon & $\begin{array}{l}\text { Negociante, vicecónsul de } \\
\text { Francia }\end{array}$ & Francés \\
\hline Juan Guilheume & Comerciante & Francés \\
\hline Juan Camon & Comerciante & Francés \\
\hline Juan Bachaulet & Botiguero & Francés \\
\hline Joseph Miran & Botigucro & Francés \\
\hline Francisco Bonafont & Comerciante & Francés \\
\hline Juan Pechinat & Tratante & Francés \\
\hline Simón Crosad & Botiguero & Francés \\
\hline Pedro Miramon & Negociante & Francés \\
\hline Carlos Matheu & Botiguero & Francés \\
\hline Andres Robellato & Botiguero & Fenovés \\
\hline Domingo Robellato & Botiguero & Genovés \\
\hline Felipe Cormi & Botiguero & Maltés \\
\hline Don Francisco Larquier Despujols & Comerciante & Francés \\
\hline Antonio Vidal & Calderero & Francés \\
\hline Antonio Laboria & Calderero & Francés \\
\hline Joseph Escarrio & Zapatero & Francés \\
\hline Francisco Dian & Marinero & Francés \\
\hline Vicente Compte & Zapatero & Napolitano \\
\hline Juan Legheume & Labrador & Francés \\
\hline Don Joseph White & Comerciante & Irlandés \\
\hline Don Simon Adley & Comerciante & Irlandés \\
\hline
\end{tabular}

Fuente: Elaboración propia en base a la documentación consultada AMV, MOA, caja 8, exp.5 (1778). APV. Libro de matrimonios, volumen IV. 1746-1775. Libros de matrimonios, volumen $\mathrm{V}$ (1776-179). AMV, MOA, caja 8, exp.6 (1781). 
Figura18. Cuadro y gráfico según la nacionalidad, el oficio y el domicilio de los extranjeros activos domiciliados en Vinaròs en 1754

\begin{tabular}{|l|l|l|l|}
\hline Nombre & Oficio & Nacionalidad & Domicilio \\
\hline Bernardo Carrera & Mercader & Francés & Calle de San Agustin \\
\hline Phelippe Legeume & Botiguero & Francés & Calle del Socorro \\
\hline Pedro Casanova & Mercader & Francés & Calle del Socorro \\
\hline Joseph Miran & Botiguero & Francés & Calle Mayor \\
\hline Simón Crosad Vilar & Botiguero & Francés & Calle Mayor \\
\hline Pedro Miramon & Negociante & Francés & Calle de los Médicos \\
\hline Matheu Cabadés & Tratante & Francés & Calle Mayor \\
\hline & & & Calle Mayor \\
\hline Jayme Camon & Negociante, vicecónsul de Francia & Francés & Calle Mayor \\
\hline Carlos Matheu & Negociante & Francés & Calle del Ángel \\
\hline Eduardo Estrich Serton & Negociante & Irlandés & Calle de los Médicos \\
\hline Antonio Vidal & Calderero & Francés & Calle del Socorro \\
\hline Juan Legeume & Labrador & Francés & Calle de los Médicos \\
\hline Juan Loustau & Negociante, privilegiado por la Real & Francés & \\
\hline
\end{tabular}

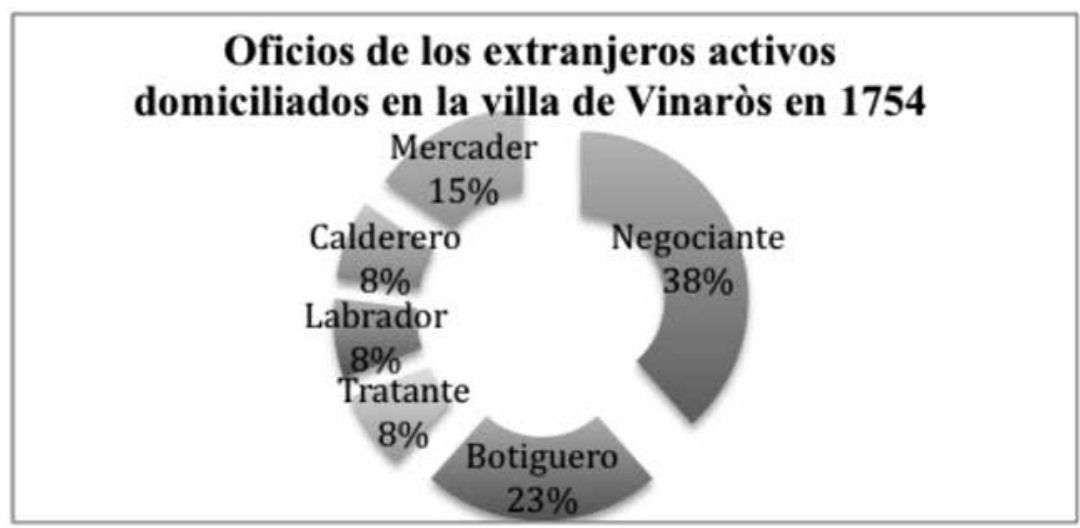

Fuente: AMV. Relación del vecindario general de la villa de Vinaròs en el año 1754. Caja X. Exp.3.

Fuente: AMV. Relación del vecindario general de la villa de Vinaròs en el año 1754. Caja X. Exp.3. 
FIGURA 19. Árbol genealógico de la familia Escrivano - Morales

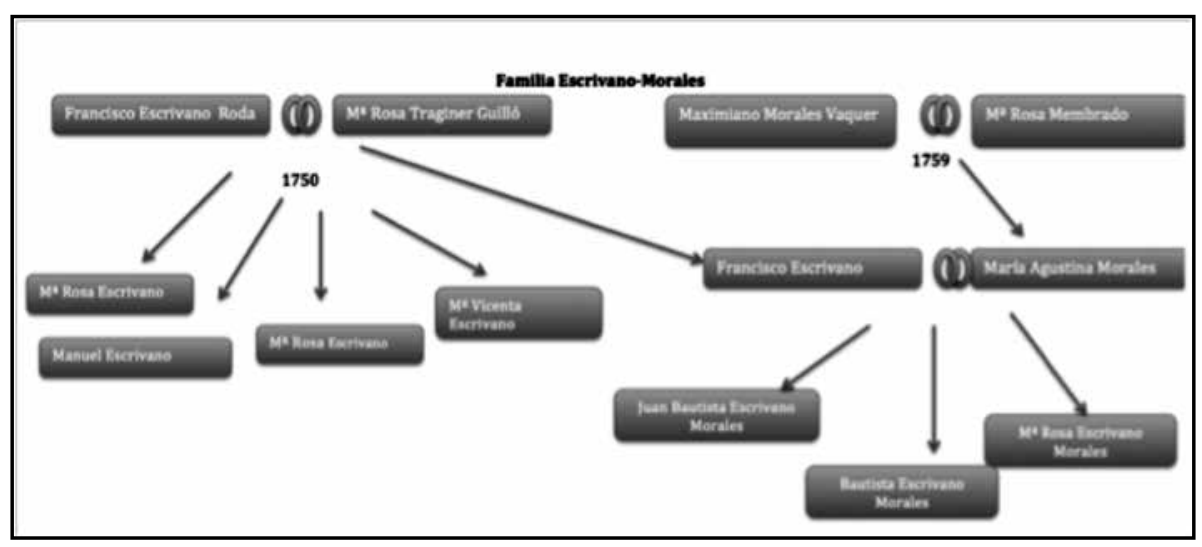

Fuente: APV. Libro de matrimonios, volumen IV. 1746-1775. Libro de matrimonios, volumen V. 1776-1795. Libro de bautismos, volumen XI. 1780-1786.

FIGURA 20. Árbol genealógico de la familia Camón - Pons Roger

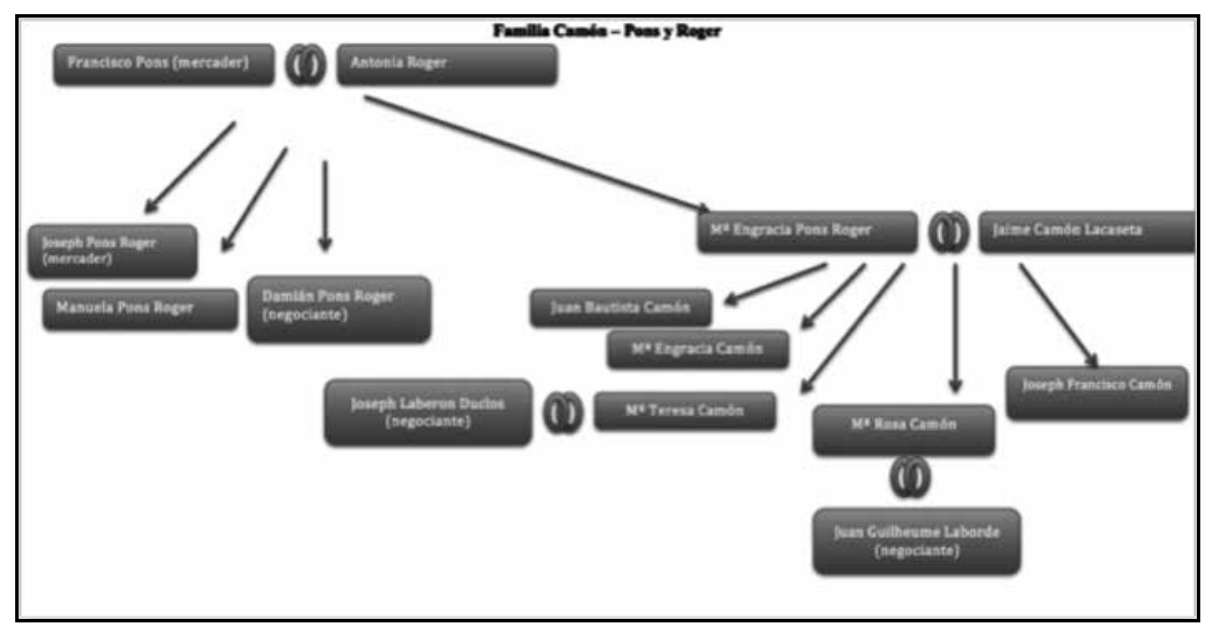

Fuente: APV. Libro de matrimonios, volumen IV.1746-1775. Libro de matrimonios, volumen III. 1715-1745. Relación del vecindario general de la villa de Vinaròs. (1754). Caja X. Exp.3. 